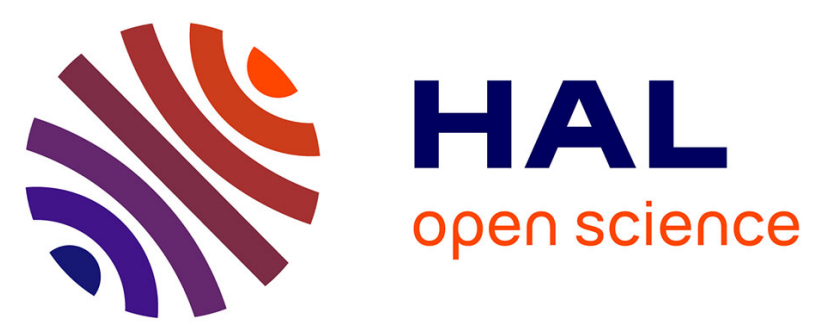

\title{
Inorganic engineered nanoparticles in drinking water treatment: a critical review
}

Konstantinos Simeonidis, Stefanos Mourdikoudis, Efthimia Kaprara, Manassis Mitrakas, Lakshminarayana Polavarapu

\section{To cite this version:}

Konstantinos Simeonidis, Stefanos Mourdikoudis, Efthimia Kaprara, Manassis Mitrakas, Lakshminarayana Polavarapu. Inorganic engineered nanoparticles in drinking water treatment: a critical review. Environmental Science: Water Research and Technology, 2016, 2, pp.43-70. 10.1039/C5EW00152H . hal-01195548

\section{HAL Id: hal-01195548 https://hal.sorbonne-universite.fr/hal-01195548}

Submitted on 8 Sep 2015

HAL is a multi-disciplinary open access archive for the deposit and dissemination of scientific research documents, whether they are published or not. The documents may come from teaching and research institutions in France or abroad, or from public or private research centers.
L'archive ouverte pluridisciplinaire HAL, est destinée au dépôt et à la diffusion de documents scientifiques de niveau recherche, publiés ou non, émanant des établissements d'enseignement et de recherche français ou étrangers, des laboratoires publics ou privés. 


\title{
Inorganic engineered nanoparticles in drinking water treatment: A critical review
}

Konstantinos Simeonidis, ${ }^{\text {a }}$ Stefanos Mourdikoudis, ${ }^{* \mathrm{bc}}$ Efthimia Kaprara, ${ }^{\mathrm{d}}$ Manassis Mitrakas, ${ }^{\text {d Lakshminarayana Polavarapu* ef }}$

${ }^{\mathrm{a} D e p a r t m e n t}$ of Mechanical Engineering, University of Thessaly, 38334, Volos, Greece

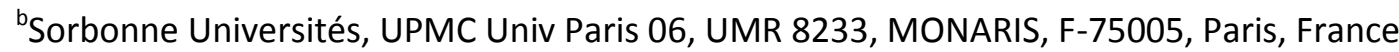

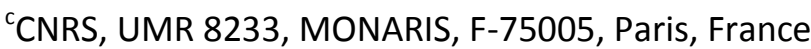

${ }^{\mathrm{d} D e p a r t m e n t}$ of Chemical Engineering, Aristotle University of Thessaloniki, 54124, Thessaloniki, Greece

${ }^{\text {e}}$ Photonics and Optoelectronics Group, Department of Physics and CeNS, LudwigMaximilians-Universität München, D-80799, Munich, Germany

${ }^{f}$ Nanosystems Initiative Munich (NIM), D-80799, Munich, Germany

\begin{abstract}
This review summarizes recent research in the field of inorganic engineered nanoparticles development with direct or potential interest for drinking water treatment. The incorporation of engineered nanoparticles in drinking water treatment technologies against the removal of heavy metals, microorganisms and organic pollutants appears as a very dynamic branch of nanotechnology. Nanoparticles owe their potential on the high specific surface area and surface reactivity compared to conventional bulk materials. Depending on the mechanism of uptake, nanoparticles can be designed to establish high selectivity against specific pollutants and provide the required efficiency for application. However, despite early encouraging results, nanoparticles meet a number of limitations to get promoted and become part of large-scale water treatment plants. The most important is their availability in the required large quantities and their efficiency to fulfil the strict regulations for drinking water consumption and environmental safety. Both deal with the particles preparation cost and the cost of treatment operation with respect to the increase of supplied water price for the consumers. Under this view, this work attempts to evaluate reported studies according to their possibility to meet reliable requirements of water technology and also suggests an experimental approach to allow validation of tested nanoparticles.
\end{abstract}

Keywords: engineered nanoparticles, drinking water treatment, heavy metals, antimicrobial activity, organic pollutants

\section{Introduction}

Following the principles and the discoveries related to the evolution of nanosciences 
during the last two decades, a wide variety of technological fields have been promoted. ${ }^{1}$ The impact was immediate and more obvious to the called high-technology applications where the demand for dimensions decrease combined with the novel electronic, optical, magnetic and mechanical properties of nanomaterials resulted in the development of new devices and methods. ${ }^{2,3}$ The expansion of nanotechnology, in these first stages, is mainly referred to the field of electronics and health sciences ${ }^{4,5,6,7,8}$ whereas its incorporation in more traditional fields of technology was limited. For instance, the adoption of nanomaterials in conventional everyday products (clothes, shoes, cosmetics, dyes), industrial, agricultural and environmental protection processes ${ }^{9,10,11}$ encounters more skepticism based on the large quantities demands combined with their relatively high cost, the need for redesign and reconstruction of process lines and the uncertainty arising by the fate and the effect of nanomaterials to the direct or indirect environmental receptors. ${ }^{12,13,14,15,16}$

Nevertheless, numerous products nowadays claim their innovation on the addition of nanomaterials which improve their physical properties. In addition, there is a significant and intense research effort on the development and optimization of nanomaterials aiming in antimicrobial or catalytic activities with high potential for environmental applications. ${ }^{17,18}$ The decontamination of flue gases from heavy metals and aromatics, ${ }^{19,20}$ the treatment of municipal and industrial wastewater for the removal of various pollutants ${ }^{21,22}$ and the purification of drinking water ${ }^{23,24}$ or recirculating blood ${ }^{25,26}$ are the major sections of investigation. Among them, the treatment of natural water for drinking purposes appears as the most challenging field directly dealing with human nutrition and health. ${ }^{27}$ In this field, any applied method should also comply with the extremely low pollutants concentrations met in natural water and the strict international legislation for human health and environmental safety. In particular, nanomaterials have been tested as media for purification, disinfection, removal of heavy metals, degradation of organic compounds and pharmaceuticals. ${ }^{28,29,30,31}$

Since the beneficiary use of nanomaterials in drinking water treatment is considered as an achievement of high importance, they should be designed to maintain the highest possible specific surface area in order to maximize surface reactivity, effective contact and uptake capacity. For this reason, the class of engineered nanoparticles, and more specifically, inorganic nanoparticles which combine relatively enhanced purification properties and high stability in water, should be preferred for water treatment. Inorganic engineered nanoparticles optimized for water treatment usually act as reaction catalysts causing the degradation, oxidation and reduction or as adsorbents which form strong bonds with specific compounds in a non-reversible way. Therefore, apart from the requirement for high surface area, the selectivity of nanoparticles for specific water purification processes should stand on the chemical affinity, the surface charge density and the electron transfer ability. However, the main drawbacks for nanoparticles use in water treatment are not directly related to their efficiency but to technical, economical and safety limitations which complicate the replacement of conventional methods.

This review presents the recent laboratory research related to the application of engineered nanoparticles consisting of inorganic phases in water treatment and their classification in the fields of heavy metal removal, antimicrobial activity and organic 
compounds degradation. Reported results are discussed not only according to their potential for application in different drinking water treatment processes but also from a critical consideration of the possibility to scale-up in technologically viable methods and become competitive to existing techniques and conventional materials. As one of the main limitations in the effort to evaluate the efficiency of nanomaterials from different authors is the absence of a unified procedure that enables direct comparison of results, this work suggests an experimental methodology working with reliable conditions and parameter ranges of drinking water treatment and generating proper indices for the validation of performance.

\section{Synthesis methods of nanoparticles}

A wide variety of methods have been used to produce nanoparticles based on traditional and modern chemical or mechanical procedures. Chemical methods usually generate nanoparticles in dispersions following the gradual size increment of small nuclei after the deposition of atoms or ions released by a chemical reaction (bottom-up). ${ }^{32}$ Nanoparticles are formed as a result of oversaturation of soluble phases when a change in their solubility occurs. Depending on the source of solubility modification, chemical methods are classified in precipitation (acidity variations), ${ }^{33}$ thermal decomposition (high temperatures), ${ }^{34}$ solvothermal (high pressure), ${ }^{35}$ sonication (supersonics) ${ }^{36}$ and electrodeposition (redox potential). ${ }^{37}$ On the opposite, in mechanical preparation routes, nanoparticles are obtained after splitting large-dimension materials in smaller units (top-down). High-energy ball-milling is the main mechanical preparation method for size reduction and preparation of single- or multiple-phase nanoparticle systems. ${ }^{38}$ Finally, spray techniques may produce nanoparticles in the vapor phase by thermal or laser assisted chemical reactions. ${ }^{39}$

In general, structural and chemical stabilization of nanoparticles are the most important requirements for a successful synthetic approach. The existence of such features ensures high surface-to-volume ratio, sufficient resistance against phase changes (e.g. oxidation) and appearance of nanoscale effects. For this reason, high quality nanoparticles preparation methods are usually based on the use of surfactants or inorganic coatings to ensure good isolation and a series of size separation and classification procedures to minimize polydispersity. However, most of these processes are not compatible to environmental applications, being even less compatible to water purification for drinking purposes.

As already mentioned, due to the high volumes of water to be treated, water purification demands proportionally high availability in nanoparticle quantities when those are qualified for the application. Therefore, the preparation cost for nanoparticles may dominate the overall cost of the treatment process. This implies that synthesis methods based on expensive reactants or working at high temperatures are not so favorable. In addition, the high toxicity and the incompatibility to aqueous processes is a serious drawback for the adoption of methods using organic metal precursors, reactants or solvents. It should be mentioned that in terms of industrial production, the accomplishment of strict environmental conditions does not only concern the obtained nanoparticles and their application in water treatment but their large-scale production line as well. 
Since water treatment reactions usually take place in active sites on the surface of the solid, another limitation in the preparation approach is related to the need for keeping the surface free of surfactants or coating layers which are usually employed to isolate or protect nanoparticles. On the contrary, the formation of nanoparticles without surfactants facilitates agglomeration anda consequentloss in effective specific surface area. Such restrictions indicate that in principle only low-cost, easily scalable, aqueous compatible and potentially environmentally friendly methods may provide nanoparticles suitable for water technology. According to previous analysis, it is concluded that chemical precipitation and mechanical size reduction should be initially considered and developed to obtain nanoparticles for water treatment. More expensive methods should be followed for secondary and selective stages when small quantities of nanoparticles are required.

\section{Applications in water treatment}

\subsection{Removal of heavy metals}

The presence of heavy metals in aqueous systems is considered a major worldwide problem related to many harmful effects on the health of humans and other life forms. ${ }^{40,41,42}$ The main threats are associated with the consumption of elements such as arsenic, lead, chromium, mercury, antimony, cadmium and nickel some of which appear in the form of soluble oxy-ions in natural water. Traditional removal methods for heavy metals are classified as relatively selective (chemical coagulation/filtration, adsorption) and nonselective (nanofiltration, reverse osmosis). Among these methods, adsorption is considered as a one of the most promising methods because metal-loaded adsorbents are more compact and generally form stronger bonds. For this reason, the use of consumable adsorbents is nowadays the dominant trend, since it is the simplest removal method. The qualification of the proper adsorbent for an individual heavy metal is based on a number of conditions defined by the uptake mechanism of its species. High chemical affinity, stabilization of positive or negative surface charge and incorporation of ion or electron exchange potential are described as possible directions of optimization. A large variety of nanostructured materials, usually in the form of inorganic engineered nanoparticles, has been studied as adsorbents for the removal of heavy metals. The main research efforts concern the use of inorganic nanoparticles such as zero-valent iron (ZVI), iron oxides $\left(\mathrm{Fe}_{3} \mathrm{O}_{4}\right.$, $\gamma$ - $\left.\mathrm{Fe}_{2} \mathrm{O}_{3}\right)$ and oxy-hydroxides $(\mathrm{FeOOH})$, some other metal oxides $\left(\mathrm{Al}_{2} \mathrm{O}_{3}, \mathrm{TiO}_{2}, \mathrm{MnO}_{2}, \mathrm{ZrO}_{2}\right.$, $\mathrm{ZnO}, \mathrm{MgO}, \mathrm{CeO}_{2}$ ) and metals or alloys ( $\left.\mathrm{Au}, \mathrm{Ag}, \mathrm{Pd}\right)$. Few of them were already promoted as commercial products in water treatment technology. The goal of this process is the reduction of residual concentration below the regulation limit set by international organizations. Depending on the established risk of each heavy metal, its concentration must comply with a different tolerance limit. For instance, the regulation limit for arsenic in E.U. countries is $10 \mu \mathrm{g} / \mathrm{L}$ while the corresponding one for mercury is $1 \mu \mathrm{g} / \mathrm{L}$. ${ }^{43}$

Iron-based nanoparticles are the most widely applied systems for the uptake of heavy metals in water. ${ }^{44}$ The combination of properties like chemical affinity to targeted oxy-ions, surface charge and redox potential together with their stability and low-cost enable their use for various cases. In addition, the magnetic behavior of phases such as $\mathrm{Fe}_{3} \mathrm{O}_{4}, \gamma-\mathrm{Fe}_{2} \mathrm{O}_{3}$ and ZVI facilitates their recovery after application. In particular, ZVI nanoparticles are 
studied for their potential to work as an agent which catalyzes the reduction of some heavy metal forms to a lower oxidation state. For instance, this approach is important in the case of hexavalent chromium where its reduction to the trivalent form results in the separation of $\mathrm{Cr}$ as insoluble hydroxides. ${ }^{45}$ However, the main drawbacks of nanoscale ZVI are the release of soluble iron ions and its susceptibility in surface oxidation. To overcome the latter issue, a protective layer for iron nanoparticles surface was employed. Chitosan-coated ZVI nanoparticles were reported for their potential to remove $\mathrm{Cr}(\mathrm{VI})$ from water by its reduction to $\mathrm{Cr}$ (III) and the simultaneous formation of a precipitate with Fe(III). ${ }^{46,47}$ Carboxymethyl cellulose, polyphenols and starch were also mentioned as stabilizers for ZVI nanoparticles oriented to $\mathrm{Cr}(\mathrm{VI})$ uptake $\mathrm{s}^{48,49,50,51}$ whereas particles supported on carbon nanotubes or graphene were also reported in an effort to avoid their aggregation. ${ }^{52,53}$ Another way to protect nanoscale $\mathrm{ZVI}$ and preserve its reducing ability for $\mathrm{Cr}(\mathrm{VI})$ was by their preparation into orange peel pith in sizes $20-80 \mathrm{~nm}^{54}$ or shear-thinning gels of xanthan gum. ${ }^{55}$ The coating of ZVI nanoparticles by a thin layer of another metal or the incorporation of bimetallic systems were also tested. ZVI nanoparticles coated by Ag or $\mathrm{Cu}$ were found to enhance their stability against corrosion ${ }^{56,57}$ whereas the galvanic coupling of $\mathrm{Fe}$ with $\mathrm{Ag}, \mathrm{Pd}$, $\mathrm{Ni}, \mathrm{Al}, \mathrm{Cu}$, Co or $\mathrm{Zn}$ is able to increase reduction rate of $\mathrm{Cr}(\mathrm{VI}) .^{58}$ Magnetite-stabilized ZVI nanoparticles also promote the increase of $\mathrm{Cr}(\mathrm{VI})$ reduction reaction. ${ }^{59}$ Nevertheless, very stable uncoated Fe nanoparticles at the size range $45-80 \mathrm{~nm}$ with significant $\mathrm{Cr}(\mathrm{VI})$ removal capacity at low concentrations were prepared by physical vapor deposition using solar beam. ${ }^{60}$ Low-cost ZVI nanoparticles prepared by scrap iron and steel pickling waste liquor were also suggested as an alternative for the complete removal of $\mathrm{Cr}(\mathrm{VI})$ from water. ${ }^{61,62}$ In general, the high reactivity of ZVI nanoparticles explains the improvement of efficiency and kinetics in $\mathrm{Cr}(\mathrm{VI})$ removal compared to granular $\mathrm{ZVI}{ }^{63,64}$ though specific interferences may play an important role. ${ }^{65}$ For this reason, $\mathrm{ZVI}$ nanoparticles are promoted for the remediation of polluted groundwater. ${ }^{66,67,68,69}$ Integrated systems for large-scale environmental remediation based on nanoscale $\mathrm{ZVI}$ have already become commercially available. Nanofer 25 produced by Nanolron has been tested for the removal of $\mathrm{Cr}(\mathrm{VI}), \mathrm{U}(\mathrm{VI})$ and chlorinated hydrocarbons from contaminated soil and groundwater. ${ }^{70}$ The reduction $^{2}$ potential of $\mathrm{ZVI}$ nanoparticles has been also reported for the uptake of $\mathrm{U}(\mathrm{VI})$ and $\mathrm{Se}(\mathrm{IV})$ from water. $^{71,72,73}$

Zero-valent iron in the form of nanoparticles is examined for the treatment of a variety of other heavy metals. Arsenic removal is favored after taking its surface oxidation and corrosion as an advantage for the adsorption of As(III) and As(V). During water treatment, ZVI gets oxidized forming in situ oxy-hydroxides and oxides with enhanced surface area, charge density and reactivity (Fig. 1). Nanoscale ZVI was used as synthesized, ${ }^{74}$ embedded on activated carbon, bentonite or chitosan nanospheres ${ }^{75,76,77}$ or surface modified by sodium dodecyl sulfate ${ }^{78}$ or humic acid. ${ }^{79}$ The mechanisms of adsorption under various $\mathrm{pH}$ conditions, the gradual modification of ZVI during the process and the possible interferences have been reported separately for $\mathrm{As}(\mathrm{III})$ and $\mathrm{As}(\mathrm{V}) .^{80,81,82,83}$ The treatment of As-polluted groundwater under aerobic and anaerobic conditions was also investigated. ${ }^{84,85} \mathrm{~A}$ significant number of studies suggest the use of nanoscale $\mathrm{ZVI}$ for the adsorption of $\mathrm{Pb}^{2+} .86,87,88,89$ Kaolinsupported ZVI nanoparticles were found similarly efficient to remove $\mathrm{Ni}^{2+}$ and $\mathrm{Cd}^{2+}$ together with $\mathrm{Pd}^{2+} \cdot{ }^{90}$ Treatment of water with high concentrations in $\mathrm{Cu}^{2+},{ }^{91,92} \mathrm{Hg}^{2+},{ }^{93} \mathrm{Co}^{2+},{ }^{24}$ 
$\mathrm{Ba}^{2+95}$ and $\mathrm{Zn}^{2+96}$ is also considered. Their good performance for multiple heavy metals was also demonstrated for water systems polluted by $\mathrm{Cr}(\mathrm{VI}), \mathrm{Mo}(\mathrm{VI}), \mathrm{Cu}^{2+}, \mathrm{Cd}^{2+}, \mathrm{U}(\mathrm{VI}) .{ }^{97,98,99,100}$

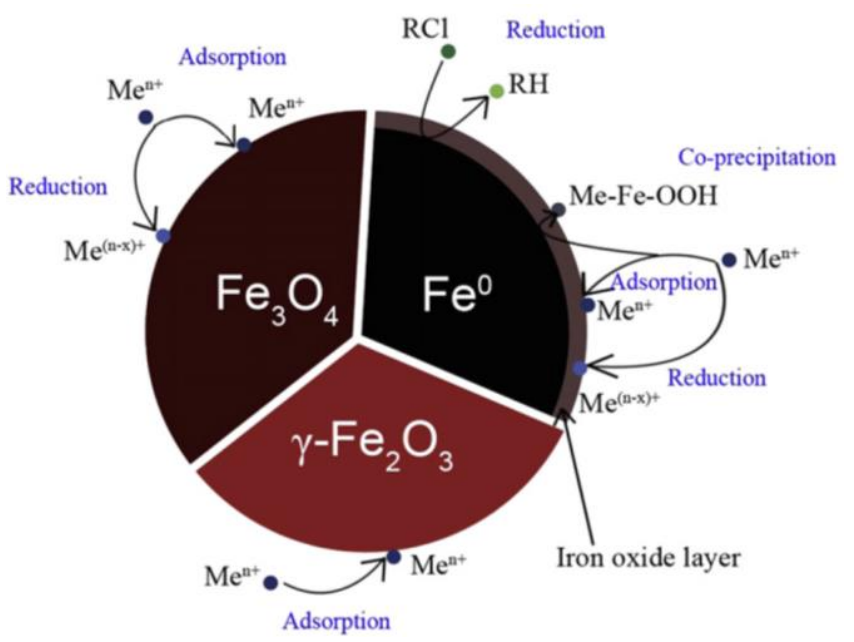

Fig. 1 Possible mechanisms of pollutants removal during water treatment by magnetic iron-based nanoparticles. ${ }^{101}$

Iron oxide nanoparticles may also provide reducing properties like those of $\mathrm{ZVI}$, but also surpass the drawback of soluble iron release. At the same time they present higher stability against structural and chemical transformation while their chemical affinity to many heavy metal oxy-ions is significant (Fig. 1). The last characteristic is important for adsorption processes where pollutants may form covalent bonds through oxygen bridges and be captured in a non-reversible way. In addition, magnetite $\left(\mathrm{Fe}_{3} \mathrm{O}_{4}\right)$ and maghemite $\left(\gamma-\mathrm{Fe}_{2} \mathrm{O}_{3}\right)$ nanoparticles provide the opportunity for their recovery and handling in water systems due to their magnetic response. Arsenic removal is the most studied case of magnetic iron oxides application in water treatment. The efficiency of oleic acid-coated $\mathrm{Fe}_{3} \mathrm{O}_{4}$ nanoparticles for the uptake of $\mathrm{As}(\mathrm{III})$ and $\mathrm{As}(\mathrm{V})$ was examined for various sizes in the range $12-300 \mathrm{~nm} .{ }^{102} \mathrm{In}$ these studies, the adsorption capacity was getting higher following the decrease in the dimensions of nanoparticles. Such observation should be related to the increase of specific surface area but also to the easier oxidation of nanoparticles surface to $\gamma-\mathrm{Fe}_{2} \mathrm{O}_{3}$ which is more efficient to arsenic adsorption than $\mathrm{Fe}_{3} \mathrm{O}_{4}$. The same group suggested the recovery of used nanoparticles using a column high-gradient magnetic separator. ${ }^{103}$ In an effort to overcome the high preparation cost of nanoparticles in these studies, an alternative method for the synthesis of low-cost and environmentally friendly magnetite nanoparticles based on everyday ingredients was examined. ${ }^{104}$ However, the coating of $\mathrm{Fe}_{3} \mathrm{O}_{4}$ by organic surfactants was found to inhibit the adsorption process. In particular, $30 \mathrm{~nm}$ magnetite nanoparticles prepared by surfactant-assisted ball-milling were inefficient to reduce $\mathrm{As}(\mathrm{III})$ and $\mathrm{As}(\mathrm{V})$ concentrations below $200 \mu \mathrm{g} / \mathrm{L} .{ }^{105}$ The same work indicated that hematite-coated $\mathrm{Fe}_{3} \mathrm{O}_{4}$ may combine improved arsenic removal capacity and the required magnetic properties for their easy recovery. Similar conclusions were obtained for nanocrystalline magnetite produced by a mechanical process and tested as arsenic adsorbent. ${ }^{106} \mathrm{~A}$ series of publications deals with the kinetic of arsenic adsorption on magnetite or mixed magnetite/maghemite nanoparticles, the role of particle concentration, $\mathrm{pH}$ and interfering ions in the process. Results suggest that $\mathrm{As}(\mathrm{III})$ and $\mathrm{As}(\mathrm{V})$ adsorption follows a first-order rate equation slightly 
affected by the ionic strength and temperature while efficiency is presented to be almost constant in the $\mathrm{pH}$ range 6-8 of typical natural water sources, reaching its maximum values below $\mathrm{pH} 4 .{ }^{107,108,109}$ As observed for magnetite/maghemite mixed nanoparticles, contact time and initial arsenic concentration determine the spontaneous adsorption process which requires at least $3 \mathrm{~h}$ to reach equilibrium. ${ }^{110}$ Among the various interferences tested, only phosphate and nitrate ions at relatively high concentrations may significantly inhibit the adsorption of arsenic on magnetite nanoparticles. ${ }^{111,112}$

Several efforts were focused on the preparation of functionalized or composite magnetite nanoparticles. Graphene oxide modified with magnetite and $\mathrm{MnO}_{2}$ nanoparticles was used as an equally efficient adsorbent for both $\mathrm{As}(\mathrm{III})$ and $\mathrm{As}(\mathrm{V})$ providing high surface area and magnetic properties. ${ }^{113}$ Magnetite nanoparticles modified by cetyltrimethylammonium bromide (CTAB), ${ }^{114}$ starch-bridged, ${ }^{115}$ ascorbic acid-coated ${ }^{116}$ or supported on boron nitride nanotubes, ${ }^{117}$ hydrotalcite, ${ }^{118}$ multiwalled carbon nanotubes ${ }^{119}$ and activated microfibrillated cellulose, ${ }^{120}$ were also evaluated for arsenic removal. The introduction of $\mathrm{Fe}_{3} \mathrm{O}_{4}$ nanoparticles obtained by wastes was another field of investigation to capture $\mathrm{As}(\mathrm{III})$ and $\mathrm{As}(\mathrm{V})$ aqueous species. ${ }^{121,122}$

Maghemite has a similar crystal structure to magnetite, but the fact that iron appears exclusively as $\mathrm{Fe}^{3+}$ and the frequent stabilization of its nanoparticles at smaller dimensions explains its higher affinity to $\mathrm{As}(\mathrm{V}) .{ }^{123}$ Electrochemically synthesized $\gamma-\mathrm{Fe}_{2} \mathrm{O}_{3}$ nanoparticles with sizes 11-23 nm indicated an endothermic $A s(V)$ adsorption limited by the mass transfer of $\mathrm{As}(\mathrm{V})$ and described by a pseudo first-order model. ${ }^{124}$ An enhancement in the removal efficiency was observed at lower particle dimensions $(6 \mathrm{~nm})$ where the oxidation of As(III) was favorable. ${ }^{125}$ Furthermore, the adsorption stability of arsenic on maghemite nanoparticles was demonstrated. ${ }^{126}$

Nanoparticles consisting of magnetic iron oxides have been widely tested for $\mathrm{Cr}(\mathrm{VI})$ removal. An overall study on the potential of $\mathrm{Fe}_{3} \mathrm{O}_{4}$ nanoparticles to be incorporated in drinking water technology was recently reported. ${ }^{127}$ Results indicate that magnetite nanoparticles may combine sufficient cost, chemical stability, improved $\mathrm{Cr}(\mathrm{VI})$ reduction ability and environmental safety after use. An integrated system for the treatment and magnetic recovery of the nanoparticles was also suggested. Preliminary adsorption kinetics of the process at various temperatures were presented elsewhere. ${ }^{128}$ Removal of $\mathrm{Cr}(\mathrm{VI})$ by mixed magnetite-maghemite nanoparticles is an endothermic process which follows an oxidation-reduction mechanism revealed by Raman and X-ray photoelectron spectroscopy measurements. ${ }^{129}$ Such systems have been also prepared on-site by an electrocoagulation process using iron electrodes into the polluted water. ${ }^{130}$ Adsorption of $\mathrm{Cr}(\mathrm{VI})$ on maghemite nanoparticles occurs by two steps: external surface diffusion followed by intra-particle diffusion. ${ }^{131}$ The effect of $\mathrm{pH}$, temperature, initial concentration and the presence of coexisting ions were examined in ref 132. Equilibrium could be reached even after $15 \mathrm{~min}$ of contact. A number of publications describe modified magnetite nanoparticle systems applied for $\mathrm{Cr}(\mathrm{VI})$ removal. Engineered biogenic magnetite nanoparticles proposed for a remediation process ${ }^{133}$ showed a high ability to reduce $\mathrm{Cr}(\mathrm{VI})$ in its trivalent nontoxic form which is stabilized in a spinel layer of the iron oxide. ${ }^{134}$ Additional studies discussing the efficiency of chitosan-coated ${ }^{135,136}$ or humic acid-coated ${ }^{137}$ magnetite nanoparticles, 
polydopamine ${ }^{138}$ or $\delta$ - $\mathrm{FeOOH}$ coated maghemite nanoparticles, ${ }^{139}$ montmorillonite, ${ }^{140}$ diatomite ${ }^{141}$ or carbon nanotubes ${ }^{142}$ supported iron oxide nanoparticles were also reported. In another case, $\mathrm{Fe}_{3} \mathrm{O}_{4}$ nanoparticles produced by an hydrothermal approach were successfully tested for $\mathrm{Cr}(\mathrm{VI})$ and $\mathrm{Pb}^{2+}$ removal from wastewater. ${ }^{143}$

Furthermore, iron oxide magnetic nanoparticles were employed for the uptake of different heavy metals. The reduction mechanisms of $\mathrm{Hg}^{2+}$ by $\mathrm{Fe}_{3} \mathrm{O}_{4}$ nanoparticles was examined in refs. 144 and 145. Magnetite nanoparticles were also tested for the uptake of $\mathrm{U}(\mathrm{VI})^{146}$ and $\mathrm{Se}(\mathrm{IV}){ }^{147}$ Functionalized $\mathrm{Fe}_{3} \mathrm{O}_{4}$ nanoparticles by amines, ${ }^{148,149,150}$ cyclodextrin, ${ }^{151}$ polymers ${ }^{152}$ and polyacrylic acid ${ }^{153}$ were used for the adsorption of $\mathrm{Cu}^{2+}, \mathrm{Cd}^{2+}, \mathrm{Pb}^{2+}, \mathrm{Ni}^{2+}$, $\mathrm{Cr}(\mathrm{VI})$ whereas combination with polypyrrole, ${ }^{154}$ silica $^{155,156}$ or humic acid ${ }^{157}$ were investigated for the uptake of $\mathrm{Cr}(\mathrm{VI}), \mathrm{U}(\mathrm{VI}), \mathrm{Hg}^{2+}, \mathrm{Pb}^{2+}, \mathrm{Cd}^{2+}, \mathrm{Cu}^{2+}$. On the other hand, $\mathrm{Mo}(\mathrm{VI})$, $\mathrm{Cu}^{2+}, \mathrm{Zn}^{2+}, \mathrm{Pb}^{2+}, \mathrm{Cd}^{2+}, \mathrm{Ni}^{2+}, \mathrm{Se}(\mathrm{IV})$ and $\mathrm{Hg}^{2+}$ were successfully adsorbed from water using maghemite-based nanoparticles. ${ }^{158,159,160,161,162,163,164,165,166}$

A number of publications for the removal of $\mathrm{As}, \mathrm{Cr}(\mathrm{VI}), \mathrm{Cu}^{2+}$, Se and $\mathrm{Co}^{2+}$ suggest ferrite nanoparticles as a magnetically activated system for water treatment. $\mathrm{MnFe}_{2} \mathrm{O}_{4},{ }^{167,168,169,170}$ $\mathrm{MgFe}_{2} \mathrm{O}_{4},{ }^{171,172} \mathrm{ZnFe}_{2} \mathrm{O}_{4},{ }^{173} \mathrm{CoFe}_{2} \mathrm{O}_{4},{ }^{174} \mathrm{NiFe}_{2} \mathrm{O}_{4}{ }^{175}$ and $\mathrm{CuFe}_{2} \mathrm{O}_{4}{ }^{176}$ have been studied in these works though the easy leaching of their components is an important drawback for application.
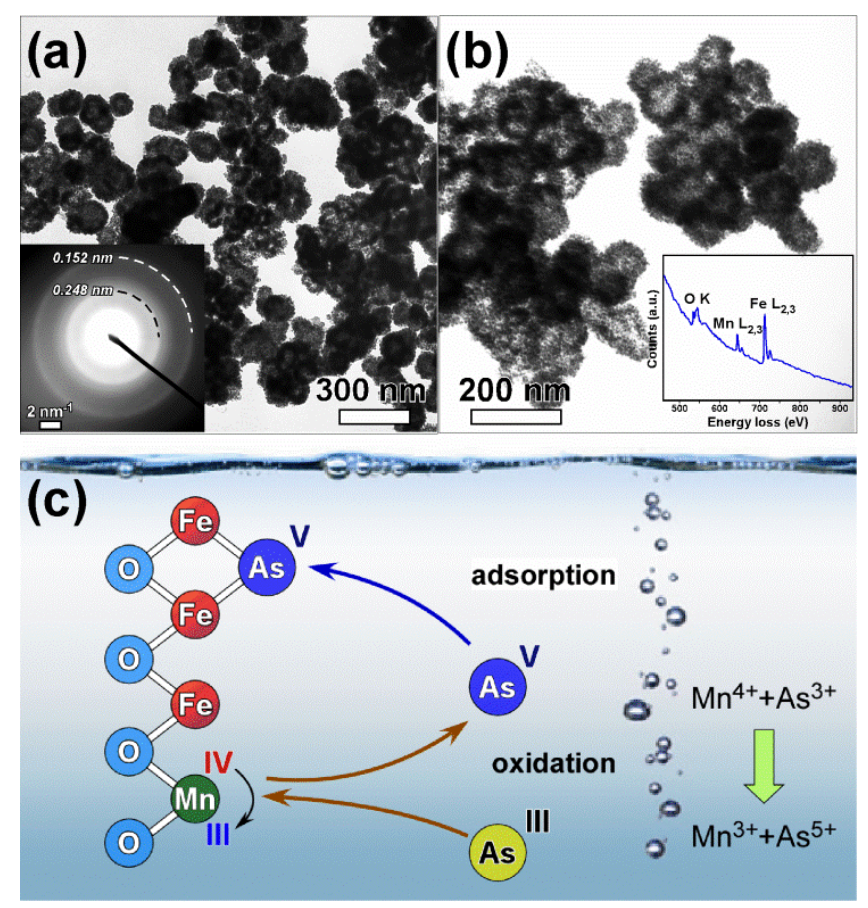

Fig. 2 Transmission electron microscopy images of hollow Fe oxyhydroxide (a) and Mn feroxyhyte nanostructures (b). Mechanism of $\mathrm{Mn}^{4+}$ mediated adsorption of $\mathrm{As}$ (III) by $\mathrm{Fe} / \mathrm{Mn}$ binary oxyhydroxides. ${ }^{191,192}$

Non-magnetic iron oxides and hydroxides are another interesting class of nanoscale materials for the removal of heavy metals from water. Hematite $\left(\alpha-\mathrm{Fe}_{2} \mathrm{O}_{3}\right)$ nanoparticles were reported for their adsorption ability against bivalent ionic forms of heavy metals including $\mathrm{Zn}^{2+}, \mathrm{Cd}^{2+}, \mathrm{Cu}^{2+}, \mathrm{Pb}^{2+} .{ }^{177}$ The mechanism of $\mathrm{Zn}^{2+}$ adsorption was further investigated 
by EXAFS spectroscopy revealing the existence of adsorption complexes. ${ }^{178}$ Their efficiency was also examined for the removal of $\mathrm{U}(\mathrm{VI})^{179}$ and $\mathrm{As}(\mathrm{V}) \cdot{ }^{180}$ Combinations of hematite nanoparticles with magnetite or scoria were also presented as adsorbents for bivalent heavy metals as well as $\mathrm{As}(\mathrm{III})$ and $\mathrm{Sb}$ (III). ${ }^{181,182,183}$ Iron oxyhydroxides and hydrated oxides in the form of granules are the most important category of heavy metal adsorbents in the market. More specifically, the high adsorption efficiency of arsenates $\left(\mathrm{H}_{2} \mathrm{AsO}_{4}{ }^{2-}\right)$ by iron oxyhydroxides is explained by the affinity of arsenic to iron combined with the positive surface charging obtained after the preparation method. ${ }^{184}$ However, only few studies describe the use of these phases as nanoparticles. In some of them, goethite nanoparticles were applied as arsenic adsorbents ${ }^{185,186,187}$ whereas ferrihydrite, akaganeite, lepidocrocite and hydrated iron oxides were evaluated for similar applications in water purification. ${ }^{188,189}$ Graphene oxide supported schwertmannite nanocomposites were used for the synergistic $\mathrm{Sb}(\mathrm{V})$ removal in another case. ${ }^{190}$

The preparation of iron oxyhydroxides under controllable slightly acidic conditions and high redox potential in a continuous flow reactor allowed the formation of hollow nanostructures consisting of schwertmannite with enhanced adsorption capacity for $\mathrm{As}(\mathrm{V}) .{ }^{191}$ Some of the authors of this review discovered that the incorporation of $\mathrm{Mn}^{4+}$ in the oxyhydroxide structure provides an oxidizing mediation mechanism which facilitates an equally high removal for As(III) using this Mn-feroxyhyte nanoadsorbent (Fig. 2). ${ }^{192,193}$ Recently, the corresponding commercial product optimized for arsenic treatment (AquAsZero) became available in the market. ${ }^{194}$ The performance of these nanoadsorbents was attributed to the positive surface charge and the ion exchange possibility of arsenic species with adsorbed sulfate ions. ${ }^{195}$ The successful removal of $\mathrm{Hg}^{2+}$ and $\mathrm{U}(\mathrm{VI})$ by single iron and binary iron/manganese oxyhydroxide nanostructures was also reported. ${ }^{196,197}$ In this case, the uptake of mercury species is favored by negatively charged adsorbents. Iron sulfide nanoparticles also showed a high potential for the adsorption of mercury as well as $\mathrm{Mn}^{2+}$. 198,199,200,201

The ability of manganese oxide $\left(\mathrm{MnO}_{2}\right)$ to favor intermediate oxidation reactions is an important property especially for the removal of As(III) species. Nanoscale $\mathrm{MnO}_{2}$ has been tested as a coating agent for modified polyether ether ketone (PEEK-WC) nanostructured capsules $^{202}$ and magnetite nanoparticles ${ }^{203}$ introducing a high removal capacity for both $\mathrm{As}(\mathrm{III})$ and $\mathrm{As}(\mathrm{V}) . \mathrm{MnO}_{2}$ nanorods combined with maghemite nanoparticles and embedded on a perlite carrier were found efficient for $\mathrm{As}(\mathrm{V})$ adsorption. ${ }^{204}$ 


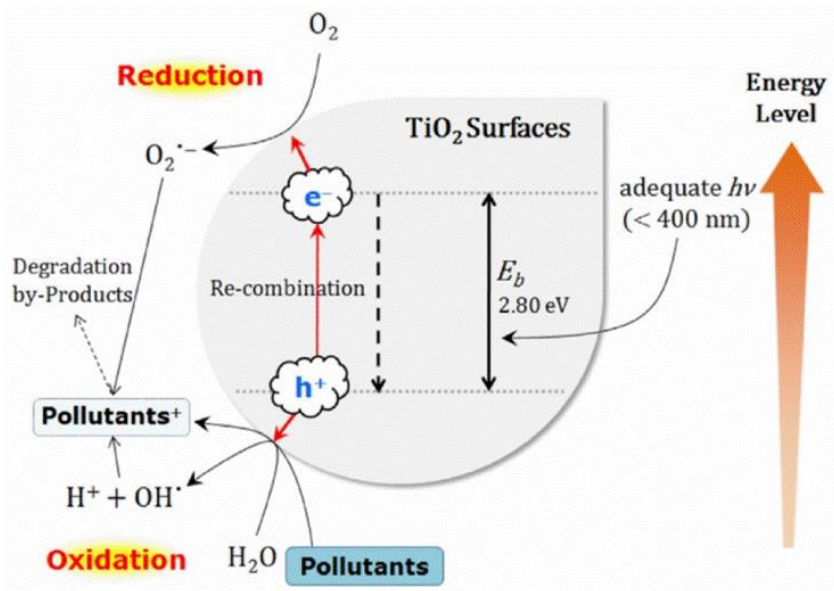

Fig. 3 Scheme depicting the pollutants removal through the formation of photoinduced charge carriers $\left(\mathrm{e}^{-} / \mathrm{h}^{+}\right)$in $\mathrm{TiO}_{2}$ nanoparticles surfaces. ${ }^{205}$

In the same direction, the photocatalytic activity of nanoscale titanium dioxide when exposed to UV radiation was exploited for the removal of various heavy metals (Fig. 3). ${ }^{205,206,207}$ Regarding arsenic, nanocrystalline $\mathrm{TiO}_{2}$ was reported to be an efficient adsorbent for $\mathrm{As}(\mathrm{V})$ and a very good photocatalyst for the oxidation of $\mathrm{As}(\mathrm{III})$ to $\mathrm{As}(\mathrm{V})$ in the presence of oxygen in sunlight. ${ }^{208}$ The mechanisms of arsenic species adsorption and the oxidation extent of $\mathrm{As}(\mathrm{III})$ have been studied at various $\mathrm{pH}$ values. ${ }^{209}$ Anatase nanoparticles $20-60 \mathrm{~nm}$ were prepared with the sol-gel method and effectively used for the removal of heavy metals, namely $\mathrm{Pb}^{2+}, \mathrm{Cu}^{2+}$ and $\mathrm{As}(\mathrm{III})$, from water. ${ }^{210} \mathrm{By}$ a similar preparation route, pure and iron-doped $\mathrm{TiO}_{2}$ nanoparticles were optimized for arsenic removal under various conditions of air and light. ${ }^{211}$ The effect of particle size in the range 6.6-30.1 nm has been reported elsewhere indicating a decrease in efficiency above $15 \mathrm{~nm}^{212}$ A partial decrease of photooxidation rate in $\mathrm{As}(\mathrm{III})$ was observed as the size increases. Arsenite removal through a simultaneous photooxidation-adsorption process was reported for $y-\mathrm{Fe}_{2} \mathrm{O}_{3} / \mathrm{TiO}_{2}$ nanoparticles. ${ }^{213}$ Remediation of groundwater from organic and inorganic arsenic was also performed by nanocrystalline $\mathrm{TiO}_{2} .{ }^{214}$ The adsorption affinity of $\mathrm{TiO}_{2}$ nanoparticles with arsenic oxy-ions was studied through the increased accumulation of As(V) in carp fish. ${ }^{215,216}$ In addition, Alizarin red $\mathrm{S}(\mathrm{ARS})$-sensitized colloidal $\mathrm{TiO}_{2}$ nanoparticles were employed in surface enhanced Raman scattering (SERS) technology to determine $\mathrm{Cr}(\mathrm{VI})$ in water. It was found that the strong coupling interaction between the dye molecules and $\mathrm{TiO}_{2}$ leads to the formation of charge-transfer complexes, therefore yielding a new electronic transition pathway for the charge-transfer process. ${ }^{217}$ Zhang et al. reported that $\mathrm{Fe}_{3} \mathrm{O}_{4} @ \mathrm{SiO}_{2} @ \mathrm{TiO}_{2}$ magnetic nanoparticles could be applied for the solid phase extraction of trace amounts of $\mathrm{Cd}^{2+}, \mathrm{Cr}(\mathrm{III}), \mathrm{Mn}^{2+}$ and $\mathrm{Cu}^{2+}$ from environmental water samples. In their approach, a lightinduced hydroxide ion emitter, malachite green carbinol base, was employed to adjust the $\mathrm{pH}$ of sample solution for quantitative adsorption. ${ }^{218}$ Importantly, aggregated $\mathrm{TiO}_{2}$ nanoparticles were commercially promoted (MetSorb, ${ }^{219}$ ADSORBSIA $^{220}$ ) for the treatment of water from As, $\mathrm{Cr}$ and Se. ${ }^{221,222} \mathrm{Zinc}$ and tin oxide nanoparticles were also mentioned to act as photocatalysts for the removal of $\mathrm{Cr}(\mathrm{VI}){ }^{223}$

Many other metal oxide nanoparticles have been suggested for heavy metal removal from water at lower occurrences. Nanostructured MgO is an excellent low-cost adsorbent 
for $\mathrm{As}(\mathrm{III}), \mathrm{As}(\mathrm{V})$ and $\mathrm{Cr}(\mathrm{VI}){ }^{224,225,226}$ Its activity is mostly based on the hydration of the external surface to $\mathrm{Mg}(\mathrm{OH})_{2}$. However, $\mathrm{MgO} / \mathrm{Mg}(\mathrm{OH})_{2}$ nanoadsorbents have the disadvantage of dissolution when working at $\mathrm{pH}$ values below 9. Cerium oxide $\left(\mathrm{CeO}_{2}\right)$ have the potential to be used for the removal of $\mathrm{Cd}^{2+}, \mathrm{Pb}^{2+}, \mathrm{Cu}^{2+}, \mathrm{As}(\mathrm{III}), \mathrm{As}(\mathrm{V})$ and $\mathrm{Cr}(\mathrm{VI})$ either in the form of individual nanoparticles, ${ }^{227,228,229,230}$ associated with $\mathrm{MnO}_{2}{ }^{231}$ nanowires ${ }^{232}$ or in porous nanospheres with $\mathrm{ZrO}_{2} \cdot{ }^{233}$ Zirconium oxide nanoparticles (also introduced as commercial product ${ }^{234}$ ) with sizes 6-10 $\mathrm{nm}$ were able to successfully capture $\mathrm{As}(\mathrm{III})$ and $\mathrm{As}(\mathrm{V})$ in a strong inner-sphere surface complex. ${ }^{235,236,237}$ The well-known efficiency of granulated alumina in $\mathrm{As}(\mathrm{III})$ and $\mathrm{As}(\mathrm{V})$ uptake was attempted to be transferred in nanostructured materials. In particular, $\gamma-\mathrm{Al}_{2} \mathrm{O}_{3}$ nanocomposites ${ }^{238}$ and alumina-supported $\mathrm{ZVI}^{239}$ were used for $\mathrm{As}(\mathrm{V})$ removal whereas $\gamma-\mathrm{Al}_{2} \mathrm{O}_{3}$ catalyzed by $\mathrm{H}_{2} \mathrm{O}_{2}$ showed good performance in the oxidation/removal of $\mathrm{As}(\mathrm{III}){ }^{240}$ Batch and column tests were performed to validate the potential applicability of $\mathrm{CuO}$ nanoparticles in arsenic removal under realistic conditions of groundwater treatment in a flow-through reactor. ${ }^{241}$ The kinetic, thermodynamic and adsorption mechanisms in this process were also analyzed. ${ }^{242,243}$

Besides, noble metal nanoparticles have also been widely tested in sensing and taskspecific applications for heavy metals capture from water despite high cost. One of the most important applications of Au nanocrystals in water treatment is the removal of mercury. Pradeep and co-workers reported the use of alumina-supported gold nanoparticles for the removal of $\mathrm{Hg}$ through the amalgamation between both metals. ${ }^{244}$ An approach for the ultrasensitive selective detection of $\mathrm{Hg}^{2+}$ and $\mathrm{CH}_{3} \mathrm{Hg}^{+}$based on fluorescence quenching of gold nanoclusters is reported in ref 245 . Similarly, the speciation between mercury and methylmercury ions was achieved by employing a SERS-sensing platform consisted of a monolayer of mercaptopyridine able to bind with gold nanoparticles anchored onto polystyrene microbeads. The coordination with mercury species took place via the nitrogen of the pyridine moiety in water. ${ }^{246}$ Another process based on amalgam formation has been used to eliminate $\mathrm{Hg}^{2+}$ from both deionized water and natural-like water with citrate-coated Au nanoparticles (Fig. 4). Although their approach was mainly effective for relatively low $\mathrm{Hg}$ concentrations, in certain cases they were able to reduce further the mercury concentration down to the levels specified for drinking water. ${ }^{247}$ More recently, a simple, fast and costeffective route to capture $\mathrm{Hg}$ was demonstrated in tap water through its amalgamation with $\mathrm{Au}$. Their method was eco-friendly thanks to the use of non-toxic ascorbic acid as a reducing agent for CTAB-coated Au nanostructures. ${ }^{248}$ Decontamination of mercury by carbon-coated magnetic Co nanoparticles was also reported. ${ }^{249}$ The selective determination of $\mathrm{Cr}(\mathrm{III})$ and $\mathrm{Cr}(\mathrm{VI})$ in tap water and wastewater was developed by another simple, economical and relatively 'green' method, based on the fluorescence quenching of glutathione-stabilized gold nanoclusters. ${ }^{250}$ Palladium-modified titanium oxide nanoparticles have also been described as excellent materials for the removal of most kinds of pollutants from potable water. TiON/PdO nanoparticles displayed a significant photocatalytic activity for the removal of As(III) from water due to the strong optoelectronic coupling between PdO and TiON, using visible light conditions. ${ }^{251} \mathrm{Pd}$ nanoparticles were also used as catalytic centers for the removal of heavy metals through reduction reactions like in the case of $\mathrm{Cr}(\mathrm{VI})$ using formic acid. $^{252}$ 
(a)

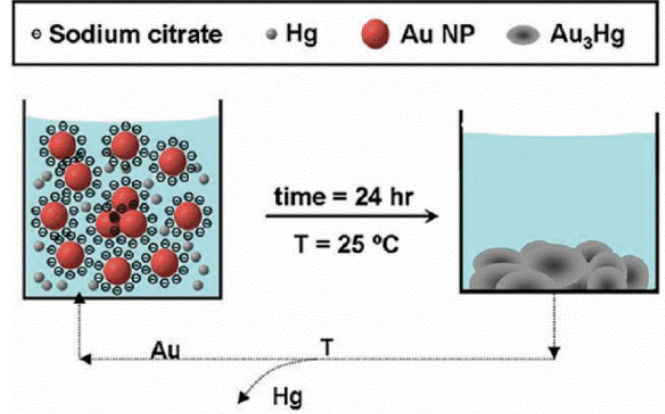

(c)

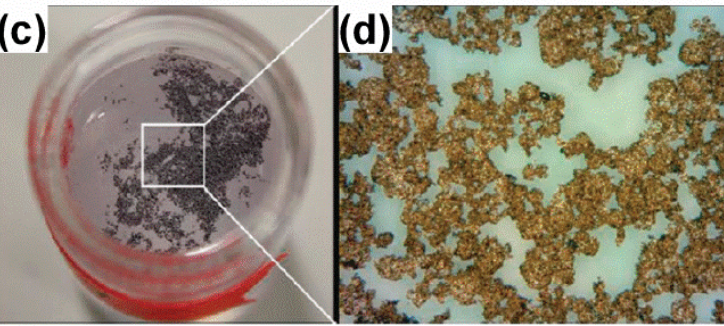

(b)

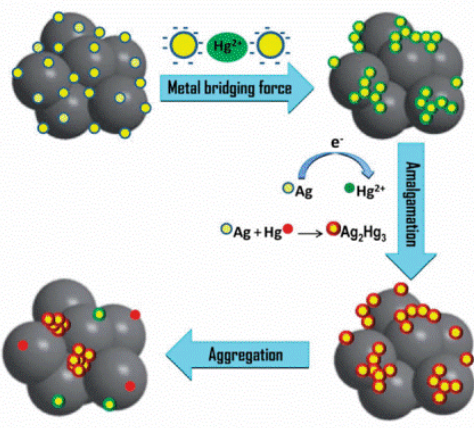

$24 \mathrm{hr}$

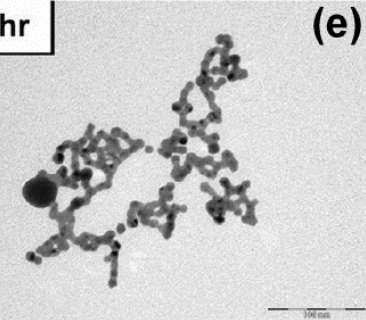

Fig. 4 Mercury elimination process through amalgamation using $A u$ nanoparticles $(a, c, d, e)$ and $\mathrm{SiO}_{2} / \mathrm{Ag}$ nanoparticles (b). ${ }^{247,262}$

The remarkable optical properties and high extinction cross-section of Ag nanoparticles allowed them to be used as colorimetric sensors as well as for the removal of toxic ions such as $\mathrm{Hg}$ and As species from water. ${ }^{253,254,255,256,257,258,259,260}$ Detection of toxic ions using $\mathrm{Ag}$ nanoparticles is based on the functionalization of Nanoparticles with specific molecules that can bind to target ions. ${ }^{254,255,256,258,259}$ For example, mercaptosuccinic acid (MSA) capped Ag nanoparticles supported on activated alumina have been used as an adsorbent for the removal of $\mathrm{Hg}^{2+}$ ions present in contaminated waters. $\mathrm{Hg}^{2+}$ ions could be removed from water by amalgamation with metals and by complexation with head groups of the monolayer surface present on nanoparticles, therefore the detection sensitivity depends on the density of functional groups on the surface. In another study, $p$ - phenylenediamine ( $p$ PDA) functionalized $\mathrm{Ag}$ nanoparticles were used for the detection of $\mathrm{Hg}^{2+}$ and $\mathrm{Fe}^{3+}$ ions in aqueous medium through the aggregation of nanoparticles upon their addition. ${ }^{261}$ Furthermore, biomolecules such as DNA (having thymine nucleotides), glutathione and cysteine have also been used as capping molecules to selectively bind with specific ions. ${ }^{254}$ For example, Wu et al. reported the preparation of oligonucleotide-functionalized silver nanoparticles for sensitive and selective detection system for $\mathrm{Hg}^{2+}$ ions via thymine ( $\mathrm{T}$ ) and $\mathrm{Hg}^{2+}$ interactions. ${ }^{260}$ Thymine molecules have strong tendency to interact with $\mathrm{Hg}^{2+}$ via $\mathrm{T}$ $\mathrm{Hg}^{2+}-\mathrm{T}$ formation and such interaction has been widely investigated in various systems. ${ }^{257}$ Similarly, Li et al. reported SERS-based selective detection of As(III) lons in aqueous media using glutathione functionalized $\mathrm{Ag}$ nanoparticles. ${ }^{255}$ Upon the addition of $\mathrm{As}(\mathrm{III}), \mathrm{Ag}$ nanoparticles tend to aggregate and the extent of aggregation depends on the concentration of As(III), which can be easily monitored by SERS using a Raman tag 4mercaptopyridine (4-MPY). Besides, unfunctionalized Ag nanoparticles have also been used to remove $\mathrm{Hg}^{2+}$ ions through the formation of amalgam. For example, silica spheres decorated with Ag nanoparticles have been used as effective sorbent for the removal of mercury from water via an amalgamation process $\left(\mathrm{Ag}_{2} \mathrm{Hg}_{3}\right)$ (Fig. $\left.4 \mathrm{~b}\right){ }^{262}$ 


\subsection{Antimicrobial activity-Disinfection}

A variety of inorganic nanoparticles were proved to be toxic against a number of microorganisms. ${ }^{263,264,265,266}$ Such biocidal activity could turn into an advantage for antimicrobial processes and disinfection of drinking water. Among all inorganic engineered nanostructures, $\mathrm{Ag}$ nanoparticles have drawn a special attention due to their excellent antibacterial and antifungal activity. ${ }^{267,268,269,270,271,272,273,274,275,276,277,278}$ The main advantage of silver nanoparticles is the combination of high selectivity for specific microorganisms and easy penetration in biological entities due to their small size. Therefore, the relatively high cost of Ag nanoparticles can be counterbalanced by the provided accuracy, efficiency and limitation in byproducts compared to traditional water disinfectants. More particularly, their antimicrobial activity could be applied for the preventive disinfection of drinking water treatment infrastructures (e.g. filters, column beds) or sites with limited sanitation care and high risk of pathogens development (third world countries).

Since ancient times, silver has been widely used for the fabrication of utensils, which allow the preservation of food products and disinfection of water. ${ }^{279,280,281}$ The high specific surface area provided by nanoparticles and the fact they can penetrate deeper and thus can purify water from pathogens such as bacteria, fungi and viruses, ${ }^{282}$ triggered the development of nanoscale research in this direction. ${ }^{283}$ Over the years, a great amount of research has been carried out by researchers around the globe to understand the antibacterial activity of zero-valent $\mathrm{Ag}$ nanoparticles and $\mathrm{Ag}^{+}$ions and to implement them in broad range of products, including medical devices, food products, clothing, cosmetics, sunscreens, paints and in wastewater treatment plants. For example, Ag nanoparticles have been extensively used in biomedical products for wound dressing, treatment of burns and bacterial infections, diagnostics and surgery. The majority of the $\mathrm{Ag}$ nanoparticle-based products that we use in our daily lives is based on their excellent antimicrobial activity. During the last decade, significant research efforts have been devoted toward the development of $\mathrm{Ag}$ nanoparticles-based products for the purification of drinking water. ${ }^{207,279,284,285,286,287,288,289,290,291,292,293,294,295,296}$ In this section, we review the proposed mechanisms for the excellent antimicrobial activity of Ag nanoparticles and recent advances made toward the development of various Ag nanoparticle-based products for drinking water purification.

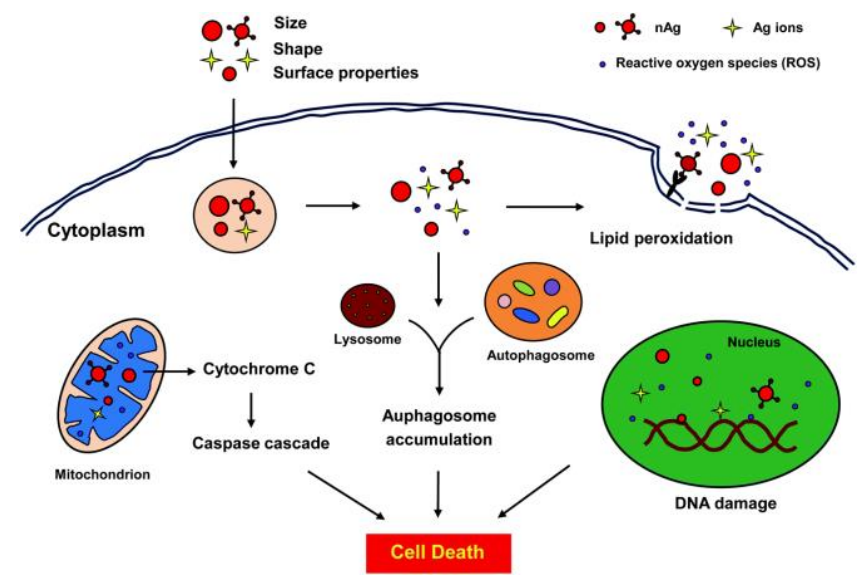

Fig. 5 Possible antimicrobial interactions of Ag nanoparticles in cells. ${ }^{272}$ 
The mechanism behind the antibacterial activity has been well investigated and various mechanistic paths have been proposed. ${ }^{267,272,276}$ Compared to metal ions, metal nanoparticles have strong tendency to interact with cell surface and pass through cell membrane. In addition, the high surface area of nanoparticles allows to functionalize them with antibodies and target specific cell types in order to inhibit the growth of infected cells without affecting the normal cells. Several studies have shown that the generation of reactive oxygen species (ROS) and oxidative stress cells were the two major mechanisms responsible for the toxicity or antibacterial activity of Ag nanoparticles (Fig. 5). ${ }^{272}$ The presence of Ag nanoparticles leads to the breakage of cell membrane at endocytosis and other parts, through which nanoparticles or ions penetrate into the cells. Subsequently $\mathrm{Ag}$ nanoparticles react with other species in cell matrix, such as proteins or glutathione to generate ROS or hydroxyl radicals via Fenton reactions. The excess of generated ROS eventually leads to cell death through the destruction of several species inside cell matrix, as shown in Fig. $5 .{ }^{272}$ For instance, the generated ROS could damage the DNA by the inhibition of cell growth, by the activation of signaling cascades in mitochondrial pathway or by lipid peroxidation. ${ }^{272}$ The mechanism of antibacterial activity at the molecular level has been further investigated by the identification of biomolecules in comparison with model compounds through SERS. The SERS results suggest that there is significant interaction of $\mathrm{Ag}$ nanoparticles with proteins through metabolic processes of purine. ${ }^{276}$ Besides, Li et al. investigated the mechanism for the antibacterial activity of Ag nanoparticles on Escherichia coli using transmission electron microscopy. ${ }^{267}$ They have found that the presence of $\mathrm{Ag}$ nanoparticles leads to the destruction of cell membrane and hinders the activity of some enzymes, which cause the bacteria to eventually die.

In general, antibacterial activity of Ag nanoparticles depends on their size, morphology and surface chemistry. ${ }^{271,273,275,276,297,298,299}$ Agnihotri et al. have studied the size dependent antibacterial efficiency of $\mathrm{Ag}$ nanoparticles of size ranging from 5-100 $\mathrm{nm}$ and they found that particles smaller than $10 \mathrm{~nm}$ showed significant performance, with the $5 \mathrm{~nm}$ particles showing the highest efficiency. ${ }^{271}$ They have also found that Escherichia coli MTCC 443 and Staphylococcus aureus NCIM 5201 were the most and least sensitive strains to $\mathrm{Ag}$ nanoparticles respectively regardless of their size. In addition, the surface chemistry of nanoparticles plays an important role in their antibacterial activity as well as toxicity. For instance, Kora et al. studied the antibacterial efficiency of Ag nanoparticles prepared with two natural plant gums (gum ghatti and gum olibanum) against gram-negative and grampositive bacteria and they found that antibacterial efficiency and cytotoxicity of the $\mathrm{Ag}$ nanoparticles prepared with gum ghatti was higher than the particles prepared with gum olibanum. ${ }^{274}$ In another study, the role of surface chemistry on cytotoxicity of $\mathrm{Ag}$ nanoparticles was investigated revealing that the capping molecules, the type of surface facets and sample aging could influence the toxicity of Ag nanoparticles. ${ }^{297}$ In addition, the incorporation of $\mathrm{Ag}$ nanoparticles into other materials such as graphene oxide, carbon and polymers induced a higher antibacterial efficiency. ${ }^{270,300}$ On this, Bao et al. reported the antibacterial properties of $\mathrm{Ag}$ nanoparticle-graphene oxide nanosheet composites against Escherichia coli and Staphylococcus aureus bacterial strains ${ }^{270}$ concluding that the composites exhibit higher activity than pure graphene oxide. Similarly, the synthesis of polyvinyl alcohol/aminopropyltriethoxysilane hybrid materials with embedded silver 
nanoparticles by sol-gel method for antimicrobial applications was reported. ${ }^{301}$ The advantage of such composite materials is that they can be easily deposited on ceramic membrane to be used for water disinfection. In addition, optimum amount of Ag could be embedded into hybrid materials in order to reduce the cytotoxicity while preserving the antimicrobial efficiency. For instance, Ag nanoparticles decorated on carbon nanotubes showed effective antibacterial activity to prevent the bacterial growth while they maintained minimum cytotoxicity. ${ }^{302}$ As a result of significant efforts from the researchers worldwide, it is very clear that Ag nanoparticles are promising candidates for antibacterial applications. However one should also take into account that the increase in the use of $\mathrm{Ag}$ nanoparticles-based products can affect human health due to high cytotoxicity. A recent review by Liu and co-workers explained the mechanism of dose- (low and high) dependent toxic effects of Ag nanoparticles with more emphasis on sublethal effects (low doses). ${ }^{272}$ So, it is very important to consider this issue and try to reduce the side effects of $\mathrm{Ag}$ nanoparticles-based antibacterial agents.

Over the last decade, significant progress has been devoted to the development of various kinds of $\mathrm{Ag}$ nanoparticles-based water purifiers and some of the related products have been commercialized. In order to develop such products, Ag nanoparticles have been incorporated into robust and porous supports, including paper, ceramics, biopolymers, calcium carbonate and carbon. ${ }^{207,279,280,284,285,286,287,288,289,290,291,292,293,294,296,297,303}$ Among all, ceramic materials have been widely used as support material for low-cost point-of-use water purification as they are relatively cheap and easy to prepare. ${ }^{207,288,291,293,304} \mathrm{~A}$ review by Kim and Van der Bruggen discussed the fabrication and use of nanoparticles in polymeric and ceramic membrane structures for water purification. ${ }^{207}$ For example, cylindrical colloidalsilver-impregnated ceramic filters for household (point-of-use) water treatment have been manufactured. ${ }^{291}$ The filters were porous (diameters ranging from 0.02 to $15 \mu \mathrm{m}$ ) and they were able to remove nearly $100 \%$ bacteria (E. Coli) upon water filtration. Very recently, a porous ceramic tablet impregnated with Ag nanopatches for house-hold water purification was reported. Such ceramic tablets could be dropped into water storage container to release Ag ions that kills bacteria. ${ }^{293}$ It was found that the amount of Ag released was repeatable for $10 \mathrm{~L}$ of water daily for 154 days and the amount was well below the World Health Organization drinking water standard for silver $(0.1 \mathrm{mg} / \mathrm{L})$. Elsewhere, biopolymers have been used as support materials to reduce cytotoxicity effects. A water filter based on biopolymer-reinforced synthetic granular nanocomposites for point-of-use water purification was developed (Fig. 6). ${ }^{279}$ The prepared nanocomposites exhibiting river sandlike properties were easy to prepare in water itself, and constantly release Ag ions. Such composites can effectively remove $E$. coli, $\mathrm{Fe}^{2+}, \mathrm{Pb}^{2+}$, and $\mathrm{As}^{5+}$ from water and they have been used to manufacture an affordable water purifier providing clean drinking water at US $\$ 2.5 / y$ per family. Besides, cellulose materials have been extensively used as low cost support materials to Ag nanoparticles for water purification. For instance, Dankovich et al. designed low-cost bactericidal paper embedded with Ag nanoparticles for point-of-use water purification (Fig. 6c). ${ }^{294}$ Such paper was used as a water filter and it was able to remove bacteria completely, while the silver release from the Ag Nanoparticles was below $0.1 \mathrm{ppm}$. Similarly, woven fabric microfiltration membranes embedded with $\mathrm{Ag}$ nanoparticles have also been used as water filters. ${ }^{287}$ As shown in Fig. $6 \mathrm{~d}$, the membranes 
turn into brown-yellow after the incorporation of Ag nanoparticles. The coated membranes were more hydrophilic showing higher water permeability and $100 \%$ removal of bacterial load from drinking water. Besides, Ag nanoparticles could be incorporated into cellulose paper by microwave irradiation (Fig. 6e). ${ }^{290}$ Such paper sheets could be fixed to containers of different models to filter the contaminated water providing excellent antibacterial activity against Escherichia coli and Enterococci faecalis bacteria in deionized water or suspensions (Fig. 6e). Overall, the reported studies indicate that the supported-Ag nanoparticles can be easily incorporated into drinking water purifiers so as to deliver safe and clean water at low cost. Nevertheless, the large demands in nanoparticles availability and the high microbial loading during disinfection of drinking water still limits Ag nanoparticles either for household (point-of-use) water treatment or when specialized treatment is required.

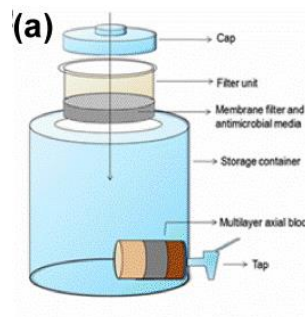

(c)

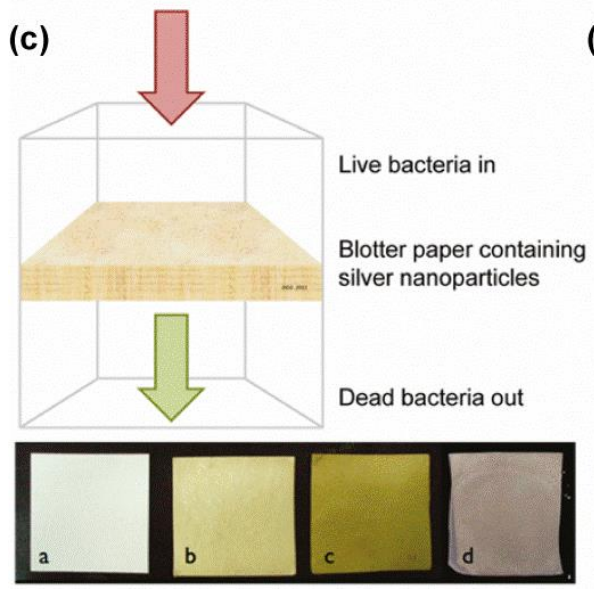

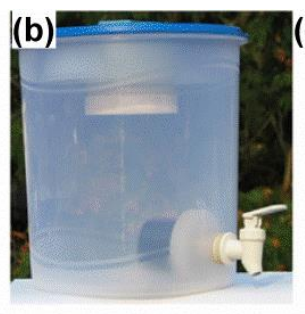

(e)
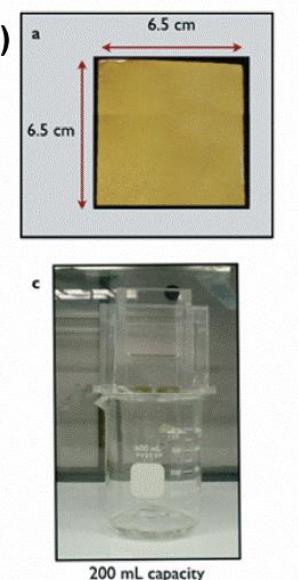
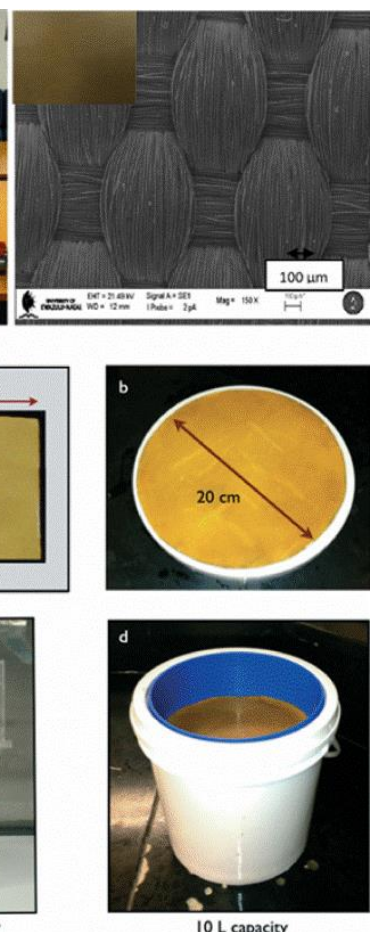

Fig. 6 Water purification systems using supported Ag nanoparticles into biopolymer-reinforced synthetic granular nanocomposites $(a, b),{ }^{279}$ bactericidal paper impregnated with Ag nanoparticles (c) ${ }^{293}$ woven fabric microfiltration gravity filter (d) ${ }^{287}$ and Ag nanoparticles-doped paper (e). ${ }^{290}$

The antimicrobial activity of several other types of nanostructures has been also highlighted. ${ }^{305} \mathrm{He}$ et al. reported the combination of Au nanoparticles with $\mathrm{ZnO}$ ones to form hybrid nanostructures with enhanced photocatalytic and antimicrobial activity. The enhancement effect might be assigned to a higher efficiency of electron transport and charge carrier separation induced by Au nanoparticles. ${ }^{306}$ Additionally, the synthesis of $\mathrm{Au}$ nanoparticles on the surface of $R$. oryzae fungus provided active nanoparticles against different bacteria and yeasts being able to absorb organophosphorous pesticides. ${ }^{307}$ On the other hand, a colorimetric assay using gold nanoparticles for the fast detection of Salmonella was developed. ${ }^{308}$ In another case, Au nanoparticles were decorated on the surface of $\mathrm{Fe}_{3} \mathrm{O}_{4} @ \mathrm{TiO}_{2}$ microspheres, enhancing their photocatalytic activity, thus yielding a better ability for organic molecules degradation and antibacterial yield in water. ${ }^{309}$ 
The antimicrobial activity of $\mathrm{TiO}_{2}$ nanostructures is also widely demonstrated in literature. Alrousan et al. have compared the photocatalytic inactivation rate of Escherichia coli between samples of surface and distilled water using immobilized titania nanoparticle films. The presence of organic and inorganic species at surface water was responsible for a decreased disinfection rate in that case. ${ }^{310}$ E. coli was used as a model organism in a systematic study on the toxicity of titania nanoparticles, studying the influence of a range of sizes, crystal structures and water chemistry conditions. ${ }^{311}$ In addition to bacteria, virus inactivation in drinking water has also been achieved using $\mathrm{TiO}_{2}$-based nanoparticles. More specifically, silica-decorated $\mathrm{TiO}_{2}$ nanocomposites inactivated the MS2 bacteriophage virus via a simple, low-cost and green photocatalytic process. ${ }^{312}$ Actually, a promising antibacterial activity against $E$. coli was also demonstrated using $\mathrm{TiO}_{2}$ nanoparticles-decorated cellulose fibers. These paper matrices displayed in addition an excellent photocatalytic performance on the degradation of methyl orange dye. ${ }^{313}$ Elsewhere, cellulose acetate membranes were coated with $\mathrm{TiO}_{2}$ nanoparticles thus forming composite materials able to remove turbidity and color in drinking water in a satisfactory extent. ${ }^{314}$ The role of $\mathrm{TiO}_{2}, \mathrm{ZnO}$ and other nanostructure systems as antimicrobial agents in drinking water treatment together with a discussion on the combination of conventional approaches with nanotechnology has been described by Alvarez and colleagues. ${ }^{264}$

The combination of $\mathrm{Ag}$ with $\mathrm{TiO}_{2}$ has been reported to often provide excellent nanomaterials with enhanced photocatalytic properties thanks to arising synergistic effects from both components. The use of Ag-doped $\mathrm{TiO}_{2}$ nanoparticles for the inactivation of MS2, and an increased photocatalytic activity was attributed to a possible synergetic effect between silver and titania. ${ }^{315}$ The visible-light-assisted antimicrobial activity of $\mathrm{Ag}$ nanoparticles-chitosan- $\mathrm{TiO}_{2}$ composites was deeply studied, suggesting also some insights on the antimicrobial mechanism taking place. ${ }^{316}$ In agreement with the existence of such synergistic effects, $\mathrm{Ag}-\mathrm{TiO}_{2}$ nanoparticles were reported to perform better than their single counterparts in the inactivation of putida and subtilis bacteria, either in the absence or in the presence of light. ${ }^{317}$ In fact, the modification of titania nanoparticles with silver as a dopant enables the use of visible light, due to the fact that individual $\mathrm{TiO}_{2}$ can be photoactivated only in wavelength values below $387 \mathrm{~nm}$. This was also exploited by Younas and colleagues who found that nanoscale $1 \% \mathrm{Ag}-\mathrm{TiO}_{2}$ was very effective on the photocatalysis of E. coli by simply applying visible light. ${ }^{318}$ Similar conclusions were deduced by investigating the bactericidal ability of $\mathrm{TiO}_{2}$ and $\mathrm{Ag}-\mathrm{TiO}_{2}$ prepared by co-precipitation method ${ }^{319}$. In addition, immobilized $\mathrm{Ag}-\mathrm{TiO}_{2}$ nanoparticles onto polystyrene waste were used as cheap and environmentally benign agents for the removal of $E$. coli and Aspergillus niger together with $\mathrm{Cr}(\mathrm{VI})$ and methylene blue from water. ${ }^{320}$ Actually, mesoporous anatase $\mathrm{TiO}_{2}$ modified with Ag nanoparticles was also reported to possess a great and recyclable capacity to degrade Rhodamine B dye and E. coli under UV light irradiation, using relatively low silver concentrations. $^{304}$

Several iron-based nanoparticles have been studied for their influence in microbe inactivation. Zero-valent iron nanoparticles appeared to be toxic against a number of bacterial cells including gram-negative Escherichia coli, ${ }^{321}$ gram-positive Bacillus subtilis, ${ }^{322}$ gram-negative Pseudomonas fluorescens, and the fungus Aspergillus versicolor. ${ }^{323}$ Their antimicrobial activity lies on the corrosion of particle surface and the release of $\mathrm{Fe}^{2+}$ ions 
which reacts with intracellular oxygen and hydrogen peroxide following a Fenton reaction. ${ }^{324,325}$ In some cases, a direct interaction between microorganisms and ZVI particles surface was also observed. ${ }^{326}$ The bactericidal effect of ZVI nanoparticles was investigated under reliable natural conditions to evaluate the influence of particles aging, adsorption of polyelectrolytes or natural organic matter and $\mathrm{pH}$ variations. ${ }^{322,327,328}$ Iron oxide nanoparticles were also applied for the inactivation of Staphylococcus aureus ${ }^{329}$ and Escherichia coli. ${ }^{330}$ In the last case, the adsorption rates for various particle sizes were examined revealing faster kinetics for larger nanoparticles. Magnetite nanoparticles functionalized by carboxyl, amine and thiol groups were able to capture and remove bacteria from water. ${ }^{331}$

Another important kind of nanomaterials known for their antimicrobial properties are some other metal oxide nanoparticles namely $\mathrm{CuO}, \mathrm{MgO}$ and $\mathrm{ZnO}$. Copper oxide nanoparticles showed significant antibacterial activity against Eschericia coli and Pseudomonas aeruginosa. ${ }^{332}$ The size dependence of their efficiency was investigated for both gram-positive and negative bacterial strains ${ }^{333,334}$ with better results observed for nanoparticles smaller than $5 \mathrm{~nm}$. Similarly, $\mathrm{MgO}$ nanoparticles presented enhanced bactericidal behavior against pathogens such as Escherichia coli, Salmonella Stanley ${ }^{335}$, Bacillus subtilis and Staphylococcus aureus. ${ }^{336}$ Their efficiency was also evaluated in comparison to other metal oxides $\left(\mathrm{Al}_{2} \mathrm{O}_{3}, \mathrm{Fe}_{2} \mathrm{O}_{3}, \mathrm{CeO}_{2}, \mathrm{ZrO}_{2}\right)$, ${ }^{337}$ supported on $\mathrm{Al}_{2} \mathrm{O}_{3}{ }^{338}$ or combined with halogen adducts. ${ }^{339}$

Many publications deal with the antimicrobial and antifungal ability of $\mathrm{ZnO}$ nanoparticles. ${ }^{340}$ Among other metal oxides, $\mathrm{ZnO}$ nanoparticles were found advantageous for the treatment of Escherichia coli, Pseudomonas aeruginosa, Staphylococcus aureus and Bacillus subtilis. ${ }^{341}$ Various synthetic conditions and particles sizes were examined for their role in the bactericidal properties. ${ }^{342,343,344,345,346,347}$ The selective antibacterial effect against Campylobacter jejuni was also proved ${ }^{348}$ while $\mathrm{ZnO}$ nanoparticles present antifungal activity for Botrytis cinerea, Penicillium expansum, ${ }^{349}$ Candida albicans ${ }^{350}$ and Aspergillus brasiliensi when applied on polyurethane membranes. ${ }^{351}$ Photoactivated ZnO nanoparticles suggest a higher antimicrobial potential when exposed to light. ${ }^{352}$ Nanocomposites with cellulose nanocrystals were also tested. ${ }^{353}$ Finally, commercially available $\mathrm{ZnO}$ nanoparticles were evaluated in comparison to $\mathrm{Ag}$ and $\mathrm{CuO}$ ones for their antibacterial efficiency and found toxic even for the beneficial environmental microbe Pseudomonas putida KT2440. ${ }^{354}$

Copper nanoparticles are another class of nanomaterials studied for the antimicrobial and antifungal properties. A variety of representative microorganisms were examined to test the efficiency of $\mathrm{Cu}$ nanoparticles whether coated by starch, ${ }^{355} \mathrm{CTAB}^{356}$ alkylamines ${ }^{357}$ or combined with soda-lime glass ${ }^{358}$ and hydrosol. ${ }^{359}$ Other examples of reported antimicrobial nanoparticles are hybrid $\mathrm{CdS} / \mathrm{Pt}_{-} \mathrm{TiO}_{2}$ nanotubes, ${ }^{360}$ nitrogen-doped $\mathrm{TiO}_{2}$ and $\mathrm{ZrO}_{2}$ nanoparticles, ${ }^{361}$ bimetallic Fe-Ag nanoparticles ${ }^{362}$ and Pd-cellulose nanohybrids. ${ }^{363}$

\subsection{Organic pollutants}

Common organic pollutants found in natural water are usually of anthropogenic source and include toxic organic compounds as chlorinated and non-chlorinated aliphatic and aromatic molecules, dyes, detergents and surfactants, pesticides, pharmaceuticals, volatile 
organic compounds (VOCs) and natural organic matter (NOM). Organohalogen pesticides, the most common class of organic contaminants in water, are implicated with several diseases, chronic damages and carcinogenicity. ${ }^{280}$ In order to remove pesticides from water, conventional methods like chemical precipitation, chemical oxidation, adsorption on powdered activated carbon and reverse osmosis are widely used. The mechanisms of removal lie on the degradation of pesticide molecules or their separation by adsorption. However, the revealing of the health risks related to organic compounds and the continuous trend for minimizing maximum contaminant levels in the sub-ppb range, raise the need for the development of removal methods with high selectivity and efficiency. The size, the high reactivity and the novel mechanisms introduced by nanoparticles enable their use as a promising technology for future application. Research is focused directly on the successful treatment of organic pollutants by nanoparticles (photocatalysis, degradation, adsorption) as well as on their detection by means of selective nanoparticle forms. An important task that should be always addressed during the treatment of organic compounds is the chemical analysis to detect secondary byproducts that could appear even more toxic. In this case, nanoparticles able to completely degrade initial pollutants or provide adsorption sites for the secondary formed molecules should be preferred. Nanoparticles with photocatalytic properties are first discussed. Monometallic Au nanoparticles were applied in a SERS-based strategy for a fast and selective detection of bisphenol $A$ in river water and Gatorade drink. ${ }^{364}$ Besides, pesticides can be also detected and in some cases removed by the use of Au nanoparticles. For instance, a process for the detection of endosulfan, chlorpyrifos and malathion via spectrophotometry using either gold or silver nanoparticles was published. The extraction of that pesticide from water was also feasible through its interaction with the nanoparticle surfaces. ${ }^{365,366}$ In fact, some by-products during the decomposition of pesticides might be more toxic than the initial compound. For this reason, Bootharaju and Pradeep tried to elucidate the degradation mechanism of the pesticide chlorpyrifos by using Au and $\mathrm{Ag}$ nanoparticles in either supported or unsupported forms. ${ }^{367}$ Au-ZnO nanocomposites prepared by a one-pot protocol exhibited an increased photocatalytic activity for the degradation of cationic and anionic dyes under sunlight irradiation. ${ }^{368}$ A special attention concerns antibiotics, as their incomplete removal from wastewaters could affect the microbial communities that occur in water ecosystems. The elimination of the antibiotic chloramphenicol (CAP) in water was achieved by using resin-supported Au-Pd nanoparticles which cleaved the carbon-halogen bond of CAP while keeping the nitro-group unaffected and this resulted in less toxic degradation products. ${ }^{369}$ Furthermore, Wong et al. illustrated the ability of bimetallic Au-Pd nanoparticles to act as superior catalysts for the hydrodechlorination of trichloroethene in groundwater. ${ }^{370}$ Gold nanoparticles were also combined with magnetic materials aiming to form another class of hybrid materials with improved features for water treatment. For instance, the role of $\mathrm{Au}$ shell in $\mathrm{Fe}_{3} \mathrm{O}_{4} @ \mathrm{Au}$ nanoparticles used for magnetic solid phase extraction was to provide a universal intermediate platform for thiol ligands with various head groups. ${ }^{371}$

The Au-doping was effective also in the case of the simultaneous removal of nitrate ions and cadmium, by using zero-valent Fe nanoparticles. In particular, a 1\% doping with gold significantly reduced the nitrite yield ratio, while maintaining an equally high $\mathrm{Cd}^{2+}$ removal capacity. ${ }^{372}$ In another approach, Au nanoparticles were conjugated with yttrium hydroxide 
fluoride nanotubes to produce nanocomposites with good SERS properties, capable to quantitatively detect and remove the Congo red dye in wastewater. ${ }^{373}$ Moreover, a porous foam of poly(dimethylsiloxane) incorporated with Au nanoparticles was developed. The resulting nanocomposite combined the properties of each component showing a high efficiency at the absorbance/removal of organic solvents, oil spills and thioanisole from water in a recyclable manner. ${ }^{374}$ More details on the role of gold nanoparticles to clean water from various pollutants were reviewed by Qian et al. ${ }^{375}$ and Wang and $\mathrm{Yu}^{376}$ while Pradeep and Anshup wrote a comprehensive article to describe the utility of all types of suitable noble metal nanoparticles for water purification. ${ }^{280}$

Titanium dioxide nanoparticles have been also proven efficient for the treatment of organic pollutants in water. In many instances, the enhancement of photocatalytic properties in the visible region has been achieved by metal implantation ( $\mathrm{Au}$ ), non-metal doping $\left(\mathrm{N}, \mathrm{C}\right.$ ) and surface organic modification. ${ }^{377}$ The combination of adsorption and $\mathrm{TiO}_{2}$ nanoparticles-based heterogeneous photocatalysis has been employed for the degradation of 2-chlorophenol. The adsorbent used was hexadecylpyridinium chloride-treated montmorillonite. ${ }^{378}$ The simultaneous use of montmorillonite and $\mathrm{TiO}_{2}$ nanocomposite films also facilitated the removal of methylene blue. ${ }^{379}$ Moreover, nanostructured glass-supported $\mathrm{N}$-doped $\mathrm{TiO}_{2}$ prepared by sol-gel synthesis was applied for the photocatalytic decolorization of methylene blue and the removal of eriochrome black-T dyes in aqueous solution. ${ }^{380}$ In fact, azo-dyes constitute around the half amount of dyes used in the textile industry, so the effluent streams generated from textile factories should be treated for the removal of such toxic residues which would otherwise be released in the environment. In this context, Filice and colleagues published the photodegradation of the azo-dye methyl orange using graphene oxide and titania nanoparticles hybrid Nafion membranes. ${ }^{381}$ The synergistic effects of adsorption, filtration and photocatalytic degradation were also illustrated for the decoloration of methylene blue in a prototype membrane reactor with $\mathrm{TiO}_{2}$ nanobelts. ${ }^{382}$ In addition, it was shown that $\mathrm{TiO}_{2}$-modified poly(vinyl alcohol)/poly(vinylidene fluoride) hollow fiber composite membranes exhibited higher dye separation efficiency and better thermal stability in comparison to their 'undoped' counterparts. ${ }^{383}$ Another study was focused on the activity of sulfur- and nitrogen-doped and undoped titania nanoparticles in the presence of inorganic anions on the degradation of dyes such as Rhodamine $B{ }^{384}$ On the other hand, $\mathrm{TiO}_{2}$ anatase-phase nanobelts synthesized with a hydrothermal method were found not only active against the decomposition of the dye malachite green, but also at the degradation of pharmaceutical and personal care products. ${ }^{385}$

A mixture of 22 organic pollutants (iopamidol, iopromide, diatrizoic acid, diclofenac, triclosan etc.) was succesfully treated in both ultrapure water and wastewater by using nano-sized $\mathrm{TiO}_{2}$ supported on single-wall carbon nanotubes. ${ }^{386}$ Furthermore, volatile organic compounds (VOCs) as methanol, acetone and benzene were photocatalytically decomposed using $\mathrm{N}$-doped $\mathrm{TiO}_{2}$ under visible and sunlight irradiation. ${ }^{387}$ The same group compared the photocatalytic performance of nanoscale titania synthesized by several sol-gel pathways (acid route, alcohol route, surfactant route) on the decomposition of mixed pesticides in drinking water concluding that the surfactant-route prepared anatase $\mathrm{TiO}_{2}$ was more suitable for this application. Their studies involved glass-supported titanium dioxide for the pesticides lindane, dichlorvos and methyl parathion. ${ }^{388}$ Doping of $\mathrm{TiO}_{2}$ nanoparticles with $\mathrm{Zn}$ 
was used to enhance efficiency for azo dyes degradation. ${ }^{389}$ Natural organic matter consists of the decomposition products of plant and animal residues. An example of NOM treatment is the degradation of fulvic acid by employing nano- and micro- scale $\mathrm{TiO}_{2}$ in a submerged membrane photocatalytic reactor. In this work, acidic $\mathrm{pH}$ conditions favored the degradation of fulvic acid. ${ }^{390}$ Another acid compound, formic acid, was effectively decomposed using titanium dioxide nanoparticles, as described by Abd Elrady et al. ${ }^{391}$ Their particles were also efficient for the inactivation of coliform bacteria in water.

Pharmaceuticals and personal care products (PPCPs) are regarded as a harmful subcategory of water contaminants as their incomplete treatment during wastewater remediation has resulted in their occurrence in surface and groundwater. This may comprise a danger for potable water as many drinking water treatment plants use source water impacted by wastewater. ${ }^{392} \mathrm{Hu}$ et al. synthesized highly entangled titania nanowires by hydrothermal method on $\mathrm{Ti}$ substrates and such porous materials were effective on the degradation of pharmaceuticals such as trimethoprim and other PPCP pollutants. ${ }^{393} \mathrm{~A}$ more recent study reported a better behavior of $\mathrm{TiO}_{2}$ nanowires in the degradation of several pharmaceuticals compared to commercial $\mathrm{TiO}_{2}$ nanoparticles. Besides, they also confirmed that anatase-phase $\mathrm{TiO}_{2}$ nanowires were more effective for the majority of the pharmaceutical compounds tested, however, for a couple of them the rutile-phase $\mathrm{TiO}_{2}$ showed a better performance. Therefore, it was concluded that the photocatalytic degradation yield varies on a PPCP and nanomaterial-specific basis. ${ }^{394}$ In fact, the presence of pharmaceutical compounds such as antibiotics in surface water could disturb the natural elementary cycles and present a potential danger when surface waters are destined for use as sources of drinking water. ${ }^{395}$ Another study presenting the efficient treatment of such compounds has to do with the photocatalytic decomposition of the antibiotic oxolinic acid in water in a range of catalyst concentrations and $\mathrm{pH}$ values. Such treatment was found fast and efficient while the residual antimicrobial activity of the by-products that remain after the photocatalytic process was limited..$^{396}$

Methylene blue was also successfully decomposed using hybrid Pd-F-doped $\mathrm{TiO}_{2}$ nanoparticles under LED visible light. The lowering of the band gap in the hybrid material was attributed to the insertion of palladium nanoparticles, while the variation in the quantity of fluorine did not cause any important changes in the band gap values. ${ }^{397}$ The synergistic effects of all components were also considered as responsible for the high photocatalytic performance of $\mathrm{Pd}$-modified $\mathrm{N}$-doped nanoscale $\mathrm{TiO}_{2}$ for the degradation of NOM. $^{398}$

It should be mentioned that the promotion of $\mathrm{TiO}_{2}$ nanoparticles in water treatment meets technological barriers related to their efficiency and application process design. For instance, as mentioned above the activation of their photocatalytic potential requires an external source of radiation or sunlight. Therefore, such processes should not be preferred in countries with low sunshine and close-packed configurations which reduce active illumination. ${ }^{399}$ Another serious issue deals with the post-recovery of nanoparticles at the end of the treatment. In order to avoid the introduction of an additional separation unit, $\mathrm{TiO}_{2}$ and other kind of nanoparticles are immobilized on glass, polymeric, ceramic and metallic substrates or supports with high specific surface area such as activated carbon, 
graphene oxide, silica, alumina, fibers, clays and zeolites. ${ }^{27,310,377,400,401,402,403,404,405,406,407,408,409,410,411,412}$ For example, glass substrates are supposed to provide transparency and as a result enhance the photo-oxidative efficiency of nanoparticles. ${ }^{413,414}$ Another advantage of immobilized $\mathrm{TiO}_{2}$ nanoparticles is the avoidance of aggregation as well as the possibility to increase the contact with hydrophobic contaminants. Nevertheless, immobilized $\mathrm{TiO}_{2}$ nanoparticles are usually less efficient compared to slurry reactors due to the reduction in specific surface and mass transfer rate. ${ }^{415,416,417}$

Iron nanoparticles are another important category studied for their efficiency in the degradation of specific organic pollutants. ${ }^{418}$ Nanoscale ZVI has been widely tested for the dechlorination of trichloroethylene in water or the remediation of contaminated sites. ${ }^{419,420,421}$ This process was reported to leave no chlorinated intermediates. ${ }^{422}$ The rate, mechanism and efficiency of dechlorination was further investigated in refs 423 and 424 whereas the effect of $\mathrm{ZVI}$ nanoparticles presence in biological degradation of trichloroethylene was also evaluated. ${ }^{425} \mathrm{ZVI}$ nanoparticles, pure or doped by $\mathrm{Pd}$, were also tested after their immobilization on alginate beads. ${ }^{426}$ In addition, bimetallic Fe-Pd nanoparticles were examined under batch laboratory experiments targeting to clarify the effect of sorption, surfactants and dissolved organic matter in the degradation of soil-sorbed trichloroethylene ${ }^{427}$ or in field assessment for chlorinated aliphatic hydrocarbons. ${ }^{428}$ The ability of bimetallic Ni/Fe nanoparticles to degrade DDT and the effect of $\mathrm{pH}$ in the observed efficiency was the subject of another study. ${ }^{429}$ Similarly, other chlorinated compounds such as lindane, atrazine, alachlor, atrazine, perchlorate or chlorophenols were successfully treated by ZVI-based nanoparticles. ${ }^{430,431,432,433,434}$ The remediation of ibuprofen, ${ }^{435}$ the removal of AB24 dye $e^{436}$ and the oxidative degradation of herbicides ${ }^{437}$ were other reported cases of ZVI nanoparticles application. Importantly, the field performance of emulsified ZVI nanoparticles for the treatment of chlorinated volatile organic compounds and solvents was monitored providing encouraging results. ${ }^{438,439}$

Pesticides can be also removed by means of iron oxide nanoparticles. However, these nanomaterials were mostly tested for their ability to adsorb organic dyes and selectively detect other organic pollutants for analysis purposes. The affinity of magnetic nanoparticles consisting of iron oxides was validated in a number of cases for organochlorine or organophosphorus pesticides, ${ }^{440,441,442}$ triazine herbicide ${ }^{443}$ and bromelain. ${ }^{444}$ Humic acid coated $\mathrm{Fe}_{3} \mathrm{O}_{4}$ nanoparticles were found efficient for the removal of sulfathiazole ${ }^{445}$ from water whereas $\mathrm{Fe}_{3} \mathrm{O}_{4} @ \mathrm{TiO}_{2}$ nanoparticles may function as sensing agent for pesticides biomarkers. ${ }^{46}$ Several research studies examined the adsorption of cationic, anionic and azo-dyes from aqueous solutions. In brief, $\mathrm{Fe}_{3} \mathrm{O}_{4}$ nanoparticles conjugated with carboxymethyl- $\beta$-cyclodextrin, ${ }^{447}$ coated by CTAB ${ }^{448}$ humic acid, ${ }^{449}$ polymers ${ }^{450}$ or chitosan ${ }^{451}$ and combined with carbon ${ }^{42,453}$ were able to adsorb a variety of representative dyes. The adsorption ability for dyes was also described for maghemite nanoparticles-based systems as well. ${ }^{454,455}$

Finally, a number of individual cases with various inorganic nanoparticles have been reported for the potential uptake or adsorption of organic pollutants from water. In particular, iron sulfide and $\mathrm{ZrO}_{2}$ nanoparticles were tested for the removal of organochlorine 
and organophosphate pesticides, respectively. ${ }^{456,457,458}$ The success of manganese oxide hollow nanostructures and $\mathrm{MgO}$ nanoparticles to remove dyes was reported in refs 459 and 460 while the photocatalytic performance of $\mathrm{Mn}$-doped $\mathrm{ZnO}$ and $\mathrm{CdS}$ nanoparticles against organic dyes was described elsewhere. ${ }^{461,462}$

\section{Fate of used nanoparticles}

Engineered nanoparticles used in water technology are usually considered as consumables even if large quantities are required. Their productive lifecycle should be determined by the working period during which an affordable efficiency in terms of pollutant removal and process cost is guaranteed. Since the small size, the high reactivity, the mobility and the relative stability of inorganic nanoparticles in aqueous conditions imply the possibility of toxic effects to the environment and the living organisms, consumed nanoparticles should be properly handled while the possible effects of their leakage should be well-known. For this reason, it is important in each application to study whether regeneration, recovery and safe disposal can be achieved. In addition, regarding their loading with toxic pollutants, any leaching or degradation behavior and chemical transformation of nanoparticles in the environment should be also assessed when designing a water treatment process.

The application of adsorbents with particle units lying in the nanoscale may introduce unknown health effects to humans and other living organisms in the accidental case of release or during their disposal. During the last years many theoretical and experimental research efforts focused on the behavior of inorganic engineered nanoparticles in aqueous or soil environment and their interaction with living organisms as a source of ecotoxicity. ${ }^{463,464,465,466,467}$ In parallel, a continuous effort to develop reproducible and standardized hazard testing methods and evaluate the human and environmental exposure to manufactured nanoparticles, is still under progress. ${ }^{468}$ The role of particles size, shape, degree of aggregation and dissolution has been examined by introducing a combination of analytical techniques. ${ }^{469,470}$ The effect of environmental factors including the $\mathrm{pH}$, the salinity and the presence of organic matter was also pronounced. ${ }^{471}$ An even larger number of works discuss the cytotoxicity of nanoparticles corresponding to human exposure enhancing the knowledge for their behavior in biological entities. ${ }^{472,473}$ Nevertheless, the conclusions are controversial and in most cases it is unclear which characteristics are responsible for celluptake and toxicity effects. ${ }^{474}$ In general, gold nanoparticles appear as the more stable but less toxic system when tested with algal and freshwater fish cells. ${ }^{475}$ Depending on their coating, Au nanoparticles could be adsorbed easier in fish cells. It has been observed that $\mathrm{TiO}_{2}$ nanoparticles provoke clastogenicity, genotoxicity, oxidative DNA damage and inflammation in vivo in mice. ${ }^{476}$ In another study, it was demonstrated that the presence of titania nanoparticles causes an increased metabolism of pentachlorophenol in zebrafish larvae, thus inducing enhanced oxidative damage in early developing fish. ${ }^{477}$ In this context, some recent research works have focused on the identification of the fate of nanoparticles employed for water purification. Schwab and colleagues have spiked $\mathrm{TiO}_{2}, \mathrm{Ag}$ and $\mathrm{ZnO}$ nanoparticles in five types of water (groundwater, freshwater and so on) and they noticed that although techniques such as membrane filtration resulted in high removals of nanoparticles, finished waters still contained detectable metal concentrations that may pose 
hazards to human health. ${ }^{478}$ Engineered $\mathrm{ZnO}$ nanoparticles may act toxic after the dissolution of $\mathrm{Zn}$ ions and the generation of active oxygen whereas photo-induced reactions may also contribute in this process. ${ }^{479}$ Clustering of $\mathrm{CeO}_{2}$ around algae cells has been mentioned as another mechanism of toxicity. ${ }^{480}$ The phytotoxicity and interactions of nanoparticles with plants during seedling is another important issue for nanoparticles sideeffects. ${ }^{481,482,483,484}$ The risk assessment after the use of zero-valent iron and iron oxide nanoparticles has been also reported in many publications concerning their phytotoxicity and seed germination. ${ }^{485,486,487}$ Surface oxidation of ZVI nanoparticles is a critical parameter for both aggregation tendency and toxicity. ${ }^{488}$

The fate of nanoparticles when released to the environment is another field of research related to their effect in several living species (Fig. 7). Most of the approaches deal with theoretical models for the transport and the transformations of nanoparticles. ${ }^{489,490}$ Gold nanoparticles were found to strongly interact with natural organic matter which causes their rapid aggregation especially under high ionic strengths. ${ }^{491}$ However, the coating of nanoparticles is responsible for the stability and removal from aquatic systems as concluded for nanoscale $\mathrm{Ag}^{492}$ Loading of ZVI nanoparticles with $\mathrm{As}$ or $\mathrm{Cr}$ after water treatment was found to enhance aggregation tendency. ${ }^{493}$ Modelling of the environmental fate of $\mathrm{TiO}_{2}$ nanoparticles in Rhine River suggests that a significant downstream transport of nanoparticles is possible with the role of suspended particulate matter being the major one in their heteroaggregation procedure. ${ }^{494}$ Importantly, the release of engineered nanoparticles in wastewaters could provide the proper substrate for their transformation to less toxic products. ${ }^{495}$ For instance, the sulfidation of $\mathrm{Ag}$ nanoparticles which is a common process in wastewater provides an insoluble and non-toxic form of silver. ${ }^{496,497}$

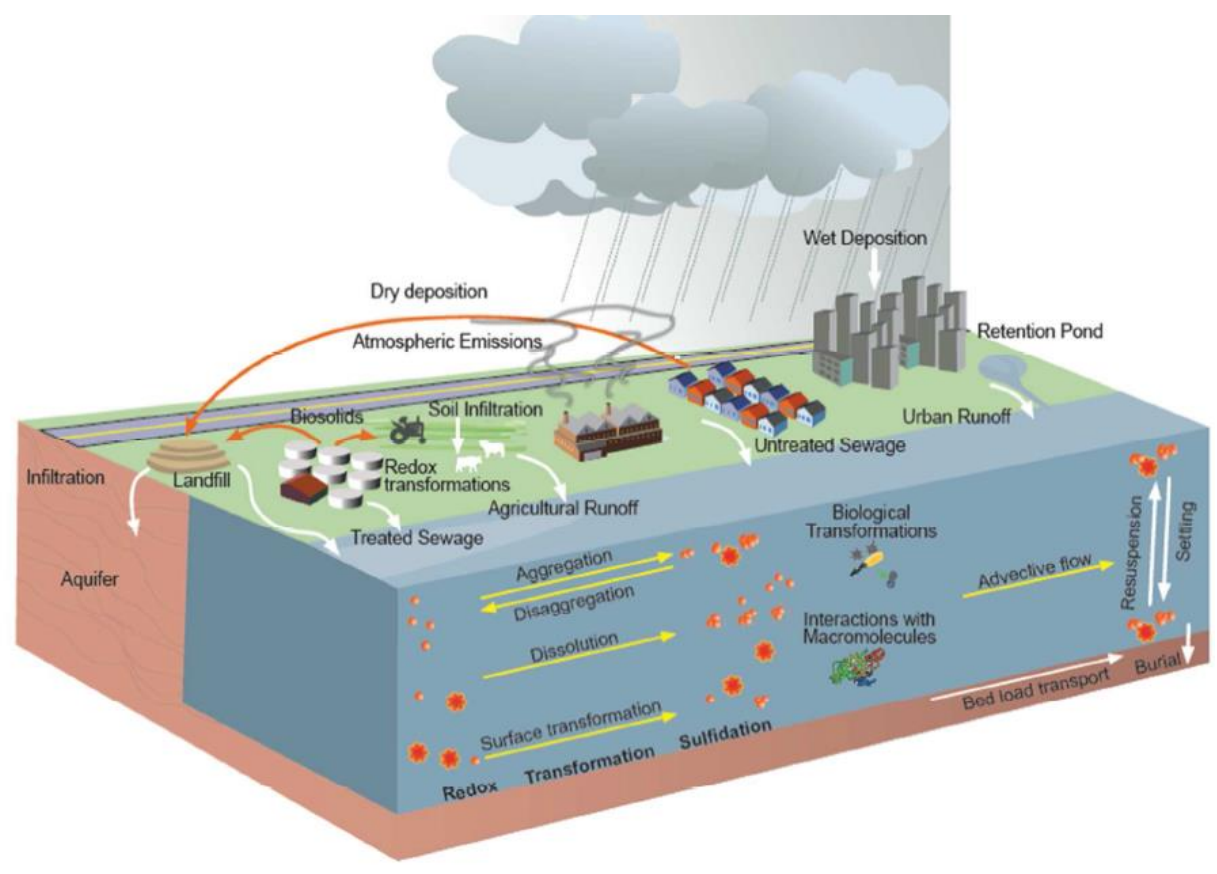

Fig. 7 Schematic representation of sources and flow of nanomaterials in the environment, and the key processes determining the fate and behavior of nanomaterials in the aquatic environments. ${ }^{489}$ 
The non-predictable behavior of nanoparticles in the environment initiates the demand for an integrated strategy for the potential risk management. ${ }^{498} \mathrm{~A}$ limited number of conventional, membrane and sorption technologies have been reported for the removal of engineering nanomaterials during water treatment. ${ }^{27}$ However, the best way to reduce potential environmental effects of nanoparticles disposal is to minimize the quantities of solids used in water treatment. It is self-evident that obtaining nanoparticles optimized and specialized in the targeted process should be the primary approach to fulfill this requirement. However, the complete or even partial regeneration of nanoparticles back to their initial state enabling their multiple reuse is a critical matter able to define the validity of the whole process. The possibility for nanoparticles recycling depends on many parameters. Among them, the mechanism of pollutant's removal (adsorption, precipitation, degradation, photocatalysis) is the most important. For instance, when nanoparticles surface is gradually covered by adsorbed molecules and ions or precipitates, a regeneration process using proper chemical reagents (e.g. $\mathrm{NaOH}$ ) should be carried. In this case, a secondary problem which has to be addressed is the treatment of the regeneration reagent which contains a concentrated quantity of the pollutant. ${ }^{499}$ When nanoparticles act as reaction catalysts, the periodical mild refreshment of surface properties is sufficient to maintain a high process yield. There are also processes where nanoparticles do not reach saturation in pollutant's loading after their usage cycle. Such systems should be designed to allow their recovery and continuous recirculation in the treatment site until saturation occurs.

Recovery of spent nanoparticles is another essential step when studying nanoparticles application in water technology. The motivation for this procedure is to ensure the absence of nanoscale solids not only in the purified water supplied to the consumers but also to the waste streams of the treatment process. Many times, the collection of dispersed nanoparticles is a very difficult task as a consequence of their small dimensions. In addition, in order to ensure their complete separation from treated water an expensive filtration step of nanofiltration should be included. ${ }^{500}$ A rather more 'conventional' approach for the removal of Nanoparticles from water is the coagulation process: nanoparticles can be enmeshed by the coagulate floc as it sediments out of the water. Coagulating agents can influence the stability of nanoparticles through the production of charged hydrolytic species that neutralize surface charges on nanoparticles. This procedure generates large nanoparticle aggregates due to the mitigation of electrostatic repulsion. ${ }^{478}$ The role of coagulant type, dose and $\mathrm{TiO}_{2}$ nanoparticles concentration was investigated upon the removal of such nanoparticles during primary water treatment. ${ }^{501}$ On the other hand, the aggregation behavior of $\mathrm{ZnO}$ and $\mathrm{TiO}_{2}$ nanoparticles in wastewater and their adverse impact on the oxygen uptake of activated sludge after an exposure time of a few hours was studied. ${ }^{502} \mathrm{~A}$ more sophisticated approach to overcome this issue is the incorporation of nanoparticles with magnetic response to external fields. ${ }^{127}$ For this reason, ZVI and iron oxide nanoparticles are preferred to be used individually or as substrates for other active phases. Magnetic separation of nanoparticles from aqueous dispersions using high-gradient fields is a widely examined subject providing many possibilities of process design. ${ }^{102,503,504,505}$

However, recovery is not the last concern of nanoparticles application. Saturated nanoparticles from water treatment are a highly toxic solid waste that needs to be safely disposed against future leakage of pollutants. ${ }^{493}$ Failure to cover this part implies to a 
dramatic increase of the whole procedure's cost since a specialized treatment of the spent nanoparticles will have to be followed. For this reason, it is critical to investigate the leaching behavior of captured pollutants following the experimental protocols that characterize solid wastes as inert, non-hazardous or toxic according to the the standard test EN $12457^{506}$ or the U.S. Toxicity Characteristic Leaching Procedure (TCLP). ${ }^{507}$ Research on the behavior of $\mathrm{ZnO}$, $\mathrm{TiO}_{2}$ and $\mathrm{Ag}$ nanoparticles indicated that their effect in the biological landfill processes is insignificant while the leachate of metal ions is primary associated with other components. ${ }^{508}$ When the strength of pollutants adsorption is enhanced, nanoparticles appear very stable against leaching even under intense conditions similar to that of a landfill. After that, saturated nanoparticles may be considered and handled as an inert waste. In the opposite case, other solutions for the inertization should be developed. An example is their application as additives in building materials, ceramics or their vitrification.

\section{Technological evaluation}

An overview of the reported research efforts dealing with the design and development of engineered nanoparticles for water treatment indicates the absence of a generalized approach for the evaluation of their efficiency. Furthermore, there are important issues related to the inappropriate methodology followed to validate their potential for drinking water purification. In general, a number of important testing conditions and quality indices should be established to allow the classification of nanoparticles properties among competitive treatment methods.

As already mentioned, drinking water purification faces much lower initial pollutant concentrations compared to wastewater treatment but also demands proportionally lower or even zero residual concentrations. For this reason, the examination of nanoparticles efficiency should be carried in the concentration range defined by the common natural water levels of the pollutant and the regulation limits for drinking water. For instance, studies for arsenic removal from drinking water should be focused on concentrations not higher than around $100 \mu \mathrm{g} / \mathrm{L}$ whereas residual concentrations below the maximum contaminant level of $10 \mu \mathrm{g} / \mathrm{L}$ should be considered after treatment. In addition, proper investigation of the corresponding kinetic rates and the presence of residual solid or toxic byproducts determines the dimensions of a treatment unit and the demand for posttreatment stages.

Another important condition to obtain reliable results during laboratory experiments is the adjustment of treatment conditions very close to those met in natural water sources. The $\mathrm{pH}$ value of water during the treatment by nanoparticles appears as the most critical parameter which significantly determines the efficiency of the process. It is very common in laboratory research to perform experiments for pollutants removal at relatively acidic $\mathrm{pH}$ values (below 5 ) where observed efficiencies are maximized. However, working at $\mathrm{pH}$ values out of the range 6-8 is not a compatible approach for drinking water treatment technology. In particular, significant variations of $\mathrm{pH}$ from its initial values may affect the physicochemical characteristics of natural water and introduce the need for an extra treatment step with chemical additives to recover drinkability for human. On the same aspect, the coexistence of common constituents of natural water may interfere with 
nanoparticles performance. Depending on the form of pollutants and the mechanism of their removal by nanoparticles, some of these anions $\left(\mathrm{HCO}_{3}{ }^{-}, \mathrm{Cl}^{-}, \mathrm{SO}_{4}{ }^{2-}, \mathrm{SiO}_{2}{ }^{-}, \mathrm{PO}_{4}{ }^{3-}\right)$ and cations $\left(\mathrm{Ca}^{2+}, \mathrm{Mg}^{2+}, \mathrm{Na}^{+}\right)$act as competitors or inhibitors of the process. In some reports, the interfering of common ions is discussed individually for each of them. However, their collective influence specifically at the concentrations usually found in natural water is rarely reported. Using natural-like water instead of distilled has been found to decrease pollutants removal efficiency by more than $50 \%{ }^{127}$ Therefore a study on nanoparticles performance should also include this information in order to provide an integrated view of their potential qualification for technological applications.

Apart from the described inconsistencies among research studies of nanoparticles consideration in water treatment, an obvious objection in the development of reported results is the absence of universal and absolute indices for the evaluation and comparison of treatment efficiency. The usual procedure, especially in heavy metals treatment, is to provide adsorption or removal isotherms after batch tests as a proof for the ability of nanoparticles to decrease pollutants concentration. Such diagrams indicate the removal capacity (Q) of the nanomaterial in terms of quantity of pollutant removed per quantity of nanoparticles added. However, authors usually point on the maximum $Q$ value, which refers to extremely high residual concentrations, as a criterion of sufficient treatment. In some other cases, the percentage of removal (residual-to-initial concentration ratio) is used to support high efficiency potential. Again, this kind of evaluation often refers to high residual concentrations from the point of drinking water demands but the quantity of added nanoparticles is not considered at all. For instance, decreasing an initial pollutant concentration from $10 \mathrm{mg} / \mathrm{L}$ to $0.5 \mathrm{mg} / \mathrm{L}$ corresponds to a $95 \%$ removal but still the residual concentration is many times above the common contaminant levels for drinking water (Fig. 8 , curve C). On the contrary, a reduction of an initial pollutant concentration of $40 \mu \mathrm{g} / \mathrm{L}$ by $70 \%$ could be acceptable. A better way to monitor nanoparticles efficiency is by the removal capacity which corresponds to the residual concentration equal to the regulation limit of each pollutant, which is actually the target value in water treatment. This index $\left(Q_{R L}\right)$ is derived after the projection of the regulation level to the adsorption or removal isotherm. Under common experimental conditions, the $\mathrm{Q}_{\mathrm{RL}}$ index may directly provide an estimation of the expected efficiency of nanoparticles according to the demands of the designed process (Fig. 8, curves A,B). 


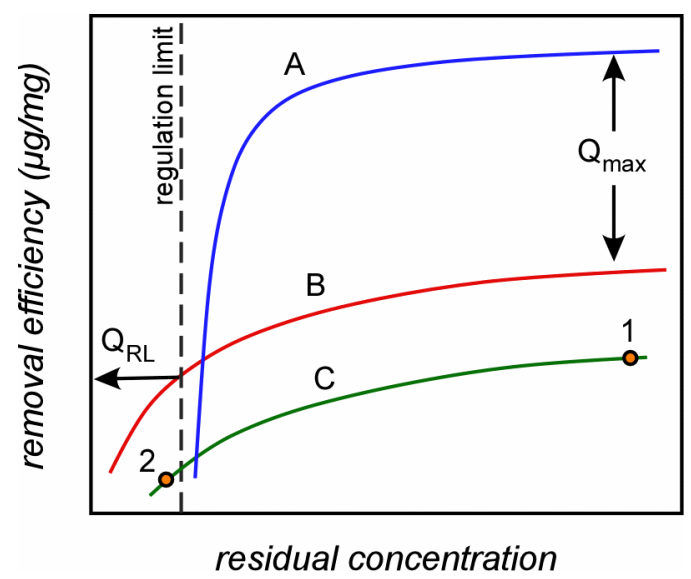

Fig. 8 Representative cases of removal isotherms for a water pollutant. Curve A corresponds to a very high $Q_{\max }$ value but a zero $Q_{R L}$. Curve $B$ indicates the determination of a high $Q_{R L}$ index though $Q_{\max }$ is relatively low. Points 1 and 2 in curve C correspond to a $95 \%$ and $70 \%$ removal from initial concentration, respectively.

However, other experimental approaches can predict nanoparticles performance more accurately than batch removal tests. Depending on the application type, the design and study of a continuous flow system for pollutant removal by dispersing nanoparticles or rapid-scale column tests when using granulated nanomaterials have been reported in this direction. ${ }^{127,193}$ This aspect is a challenge for future studies since there is not enough "knowhow' available on the design of water purification units based on nanoparticles. Considering that the main forms in which nanoparticles are employed in such processes are (i) water dispersed (slurry), (ii) immobilized on supports and (iii) granulated aggregates, a general scheme of the treatment process should be the following: In large water treatment facilities, the nanoparticles unit should be located after the primary treatment processes and just before the disinfection stage. This ensures a relatively good quality of water in the inflow of the pollutant-specific treatment by nanoparticles. A stage for the recovery or the separation of escaped nanoparticles should be also included (nanofilter, magnetic separator). In pointof-use and point-of-entry home solutions, nanoparticles should be preferably used in compact forms (grains, immobilized) as a part of filtration properly sequenced by other treatment stages so as to minimize possible interferences.

At the end, the evaluation of nanoparticles under realistic conditions is not the ultimate criterion for nanoparticles incorporation in drinking water technology. As explained, the ratio of efficiency per nanoparticles cost determines the competitiveness to other existing technologies and the possibility for commercial promotion. But still there are secondary constraints able to reject nanoparticles use in water treatment. The most important is their compliance to environmental limitations of disposal after effective lifecycle. According to these, the saturated nanoparticles should overcome successively leaching tests for solid wastes. Taking also in account their small dimensions, their safe recovery and handling should be essential information given during their study.

\section{Summary}

The summary of reported studies related with the application of inorganic engineered 
nanoparticles in water treatment indicates also the increasing interest for their development as novel products with improved performance in drinking water purification processes. Overall most of them report fundamental approaches without getting deeper in potential practical applications while some other report practical aspects without focusing on process development and only few study both sides. Depending on the properties provided by each class of nanoscale materials, research is mainly focused on their optimization as adsorbents for heavy metals, disinfectants against microorganisms or catalysts for the degradation of organic pollutants. As widely stated, the efficiency of nanoparticles in water technology is proportional to their specific area and the reactivity of their surface, i.e. the characteristics that differentiate them from materials with conventional dimensions. Therefore, one of the critical tasks in the design of engineered nanoparticles and incorporation in the technological field is to ensure stability against aggregation and chemical transformations during storing, handling and use. However, high efficiency is only one of the requirements being able to validate the competitiveness of nanoparticles in the market. Considering the strict legislation which regulates drinking water processes for the protection of human health and environment, a parallel examination of the side-effects of nanoparticles application should be successfully carried out. This corresponds to the accomplishment of a risk assessment with respect to consumer's use manner, safe disposal and potential effects in their release to the environment towards the benefits of using qualified nanoparticles in water treatment. Following the first encouraging results of nanoparticles use in a variety of water treatment applications, future research efforts should be better oriented in the evaluation of engineered nanoparticles under more reliable conditions of field application to assist their potential commercialization in large scale.

\section{Acknowledgements}

L. Polavarapu greatly acknowledges the financial support from Alexander von Humboldt foundation. The study was also implemented within the framework of the Action

"Supporting Postdoctoral Researchers" of the Operational Program "Education and Lifelong Learning" (Action's Beneficiary: General Secretariat for Research and Technology), and is cofinanced by the European Social Fund and the Greek State PE8 (135). 


\section{References}

[1] J.-L. Pautrat, Comptes Rendus Phys., 2011, 12, 605-613.

[2] X. Huang and M. A. El-Sayed, J. Adv. Res., 2010, 1, 13.

[3] M. Hasan, M. F. Huq and Z. H. Mahmood, SpringerPlus, 2013, 2, 151.

[4] B. Yu and M. Meyyappan, Solid. State. Electron., 2006, 50, 536-544.

[5] N. Collaert, A. Alian, H. Arimura, G. Boccardi, G. Eneman, J. Franco, T. Ivanov, D. Lin, R. Loo, C.

Merckling, J. Mitard, M. A. Pourghaderi, R. Rooyackers, S. Sioncke, J. W. Sun, A. Vandooren, A. Veloso, A. Verhulst, N. Waldron, L. Witters, D. Zhou, K. Barla and A. V.-Y. Thean, Microelectron. Eng., 2015, 132, 218-225.

[6 ] C. E. Handford, M. Dean, M. Spence, M. Henchion, C. T. Elliott and K. Campbell, Food Control, 2015, 57, 24-34.

[7] P. Boisseau and B. Loubaton, Comptes Rendus Phys., 2011, 12, 620-636.

[8] A. Wicki, D. Witzigmann, V. Balasubramanian and J. Huwyler, J. Control. Release, 2015, 200, 138157.

[9] F. Sanchez and K. Sobolev, Constr. Build. Mater., 2010, 24, 2060-2071.

[10] A. K. Hussein, Renew. Sustain. Energy Rev., 2015, 42, 460-476.

[11] A. Mihranyan, N. Ferraz and M. Strømme, Prog. Mater. Sci., 2012, 57, 875-910.

[12] C.-F. Chau, S.-H. Wu and G.-C. Yen, Trends Food Sci. Technol., 2007, 18, 269-280.

[13] B. Kim, C.-S. Park, M. Murayama and M. F. Hochella, Environ. Sci. Technol. 2010, 44, 7509.

[14] S. Seal and B. Karn, Saf. Sci., 2014, 63, 217-225.

[15] R. Owen and M. Depledge, Mar. Pollut. Bull., 2005, 50, 609-612.

[16] T. Sheetz, J. Vidal, T. D. Pearson and K. Lozano, Technol. Soc., 2005, 27, 329-345.

[17] M. L. W. Knetsch and L. H. Koole, Polymers, 2011, 3, 340-366.

[18] D. Astruc, F. Lu and J. R. Aranzaes, Angew. Chem. Int. Ed.., 2005, 44, 7852-7872.

[19 B.-A. Dranga, L. Lazar and H. Koeser, Catalysts, 2012, 2, 139-170.

[20] Y. Liu, D. J. A. Kelly, H. Yang, C. C. H. Lin, S. M. Kuznicki and Z. Xu, Environ. Sci. Technol., 2008, 42, 6205-6210.

[21] D. K. Tiwari, J. Behari and P. Sen, Carbon Nanotub., 2008, 3, 417-433.

[22] M. Hua, S. Zhang, B. Pan, W. Zhang, L. Lv and Q. Zhang, J. Hazard. Mater., 2012, 211-212, 317331.

[23] R. Narayan, Mater. Today, 2010, 13, 44-46.

[24] X. Qu, P. J. J. Alvarez and Q. Li, Water Res., 2013, 47, 3931-3946.

[25] I. K. Herrmann, R. E. Bernabei, M. Urner, R. N. Grass, B. Beck-Schimmer and W. J. Stark, Nephrol. Dial. Transplant., 2011, 26, 2948-2954.

[26]I. K. Herrmann, A. Schlegel, R. Graf, C. M. Schumacher, N. Senn, M. Hasler, S. Gschwind, A.-M. Hirt, D. Gunther, P.-A. Clavien, W. J. Stark and B. Beck-Schimmer, Nanoscale, 2013, 5, 8718-8723. [27] G. R. Boyd, M. E. Tuccillo, A. Sandvig, M. Pelaez, C. Han and D. D. Dionysiou, J. Am. Water WorksAssoc., 2013, 105, E699-708.

[28] I. Ali, Chem. Rev., 2012, 112, 5073-5091.

[29] P. Xu, G. M. Zeng, D. L. Huang, C. L. Feng, S. Hu, M. H. Zhao, C. Lai, Z. Wei, C. Huang, G. X. Xie and Z. F. Liu, Sci. Total Environ., 2012, 424, 1-10.

[30] A. Ayati, A. Ahmadpour, F. F. Bamoharram, B. Tanhaei, M. Manttari and M. Sillanpaa, Chemosphere, 2014, 107, 163.

[31] J. Gómez-Pastora, E. Bringas and I. Ortiz, Chem. Eng. J., 2014, 256, 187-204.

[32] C. N. R. Rao, S. R. C. Vivekchand, K. Biswas and A. Govindaraj, Dalton Trans., 2007, 3728.

[33] K. Petcharoen and A. Siriva, Mater. Sci. Eng. B, 2012, 177, 421.

[34] M. E. F. Brollo, R. Lopez-Ruiz, D. Muraca, S. J. A. Figueroa, K. R. Pirota and M. Knobel, Sci. Rep., $2014,4,6839$.

[35] J. Lai, W. Niu, R. Luque and G. Xu, Nano Today, 2015, DOI: 10.1016/j.nantod.2015.03.001

[36] A. Esmaielzadeh Kandjani, M. Farzalipour Tabriz and B. Pourabbas, Mater. Res. Bull., 2008, 43, 645.

[37] U. S. Mohanty, J. Appl. Electrochem., 2011, 41, 257.

[38] J. E. Munoz, J. Cervantes, R. Esparza and G. Rosas, J. Nanopart. Res., 2007, 9, 945.

[39] F. Iskandar, Adv. Powder Tech., 2009, 20, 283. 
[40] International Agency for Research on Cancer, IARC Monographs on the evaluation of carcinogenic risks to humans: Some drinking-water disinfectants and contaminants, Including Arsenic, Vol 84 Lyon, France (2004).

[41] F. Fernández-Luqueño, F. López-Valdez, P. Gamero-Melo, S. Luna-Suárez, E. N. Aguilera-González, A. I. Martínez, M. D. S. García-Guillermo, G. Hernández-Martínez, R. Herrera-Mendoza, M. A. ÁlvarezGarza and I. R. Pérez-Velázquez, African J. Environ. Sci. Technol., 2013, 7, 567-584.

[42] C.H. Wang, C.K. Hsiao, C.L. Chen, L.I. Hsu, H.Y. Chiou, S.Y. Chen, Y.M. Hsueh, M.M. Wu and C.J. Chen, Toxicol. Appl. Pharm., 2011, 222, 315-326.

[43] European Commission, Council Directive 98/83/EC of 3 November 1998 on the quality of water intended for human consumption.

[44] L. Li, M. Fan, R. C. Brown, J. (Hans) Van Leeuwen, J. Wang, W. Wang, Y. Song and P. Zhang, Crit. Rev. Environ. Sci. Technol., 2006, 36, 405-431.

[45] Y. T. He and S. J. Traina, Environ. Sci. Technol., 2005, 39, 4499-4504.

[46] B. Geng, Z. Jin, T. Li and X. Qi, Sci. Total Environ., 2009, 407, 4994-5000.

[47] B. Geng, Z. Jin, T. Li and X. Qi, Chemosphere, 2009, 75, 825-830.

[48] Q. Wang, H. Qian, Y. Yang, Z. Zhang, C. Naman and X. Xu, J. Contam. Hydrol., 2010, 114, 35-42.

[49] D. V. Franco, L. M. Da Silva and W. F. Jardim, Water. Air. Soil Pollut., 2009, 197, 49-60.

[50] C. Mystrioti, N. Papassiopi, A. Xenidis, D. Dermatas and M. Chrysochoou, J. Hazard. Mater., 2015, 281, 64-69.

[51] L. Alidokht, A. R. Khataee, A. Reyhanitabar and S. Oustan, Desalination, 2011, 270, 105-110.

[52] X. Lv, J. Xu, G. Jiang and X. Xu, Chemosphere, 2011, 85, 1204-1209.

[53] H. Jabeen, V. Chandra, S. Jung, J. W. Lee, K. S. Kim and S. Bin Kim, Nanoscale, 2011, 3, 3583-3585.

[54] G. López-Téllez, C. E. Barrera-Díaz, P. Balderas-Hernández, G. Roa-Morales and B. Bilyeu, Chem.

Eng. J., 2011, 173, 480-485.

[55] S. Comba and R. Sethi, Water Res., 2009, 43, 3717-3726.

[56] K. P. Singh, A. K. Singh, S. Gupta and S. Sinha, Desalination, 2011, 270, 275-284.

[57] C. Y. Hu, S. L. Lo, Y. H. Liou, Y. W. Hsu, K. Shih and C. J. Lin, Water Res., 2010, 44, 3101-3108.

[58] M. Rivero-Huguet and W. D. Marshall, J. Hazard. Mater., 2009, 169, 1081-1087.

[59] Y. Wu, J. Zhang, Y. Tong and X. Xu, J. Hazard. Mater., 2009, 172, 1640-1645.

[60] K. Simeonidis, M. Tziomaki, M. Angelakeris, C. Martinez-Boubeta, L. Balcells, C. Monty, M.

Mitrakas, G. Vourlias and N. Andritsos, EPJ Web of Conferences, 2013, 40, 08007.

[61] P. V. V. V Prasad, C. Das and A. K. Golder, Can. J. Chem. Eng., 2011, 89, 1575-1582.

[62] Z. Fang, X. Qiu, R. Huang, X. Qiu and M. Li, Desalination, 2011, 280, 224-231.

[63] B. Karn, T. Kuiken and M. Otto, Environ. Health Perspect., 2009, 117, 1823-1831.

[64] M. Gheju, Water. Air. Soil Pollut., 2011, 222, 103-148.

[65] Q. Wang, N. Cissoko, M. Zhou and X. Xu, Phys. Chem. Earth, 2011, 36, 442-446.

[66] X. Li, D. W. Elliott and W. Zhang, Crit. Rev. Solid State Mater. Sci., 2006, 31, 111-122.

[67] Y. Xu and D. Zhao, Water Res., 2007, 41, 2101-2108.

[68] W. X. Zhang, J. Nanopart. Res., 2003, 5, 323-332.

[69] S.-F. Niu, Y. Liu, X.-H. Xu and Z.-H. Lou, J. Zhejiang Univ. Sci. B, 2005, 6, 1022-1027.

[70] http://www.nanoiron.cz

[71] R. A. Crane, M. Dickinson, I. C. Popescu and T. B. Scott, Water Res., 2011, 45, 2931-2942.

[72] Z.-J. Li, L. Wang, L.-Y. Yuan, C.-L. Xiao, L. Mei, L.-R. Zheng, J. Zhang, J.-H. Yang, Y.-L. Zhao, Z.-T. Zhu, Z.-F. Chai and W.-Q. Shi, J. Hazard. Mater., 2015, 290, 26-33.

[73] L. Ling, B. Pan and W. Zhang, Water Res., 2015, 71, 274-281.

[74] S. R. Kanel, J. M. Greneche and H. Choi, Environ. Sci. Technol., 2006, 40, 2045-2050.

[75] H. Zhu, Y. Jia, X. Wu and H. Wang, J. Hazard. Mater., 2009, 172, 1591-1596.

[76] L. na Shi, X. Zhang and Z. liang Chen, Water Res., 2011, 45, 886-892.

[77] A. Gupta, M. Yunus and N. Sankararamakrishnan, Chemosphere, 2012, 86, 150-155.

[78] K. R. Kim, B. T. Lee and K. W. Kim, J. Geochem. Explor., 2012, 113, 124-129.

[79] A. B. M. Giasuddin, S. R. Kanel and H. Choi, Environ. Sci. Technol., 2007, 41, 2022-2027.

[80] S. R. Kanel, B. Manning, L. Charlet and H. Choi, Environ. Sci. Technol., 2005, 39, 1291-1298.

[81] H. Dong, X. Guan and I. M. C. Lo, Water Res., 2012, 46, 4071-4080.

[82] V. Tanboonchuy, N. Grisdanurak and C. H. Liao, J. Hazard. Mater., 2012, 205-206, 40-46.

[83] V. Tanboonchuy, J. C. Hsu, N. Grisdanurak and C. H. Liao, J. Hazard. Mater., 2011, 186, 21232128. 
[84] H. Sun, L. Wang, R. Zhang, J. Sui and G. Xu, J. Hazard. Mater., 2006, 129, 297-303.

[85] S. Comba, A. Di Molfetta and R. Sethi, Water. Air. Soil Pollut., 2011, 215, 595-607.

[86] Y. Xi, M. Mallavarapu and R. Naidu, Mater. Res. Bull., 2010, 45, 1361-1367.

[87] S. A. Kim, S. Kamala-Kannan, K. J. Lee, Y. J. Park, P. J. Shea, W. H. Lee, H. M. Kim and B. T. Oh, Chem. Eng. J., 2013, 217, 54-60.

[88] S. M. Ponder, J. G. Darab and T. E. Mallouk, Environ. Sci. Technol., 2000, 34, 2564-2569.

[89] X. Zhang, S. Lin, Z. Chen, M. Megharaj and R. Naidu, Water Res., 2011, 45, 3481-3488.

[90] X. Zhang, S. Lin, X. Q. Lu and Z. L. Chen, Chem. Eng. J., 2010, 163, 243-248.

[91] S. Xiao, H. Ma, M. Shen, S. Wang, Q. Huang and X. Shi, Colloid. Surface A., 2011, 381, 48-54.

[92] A. Ayob, N. Ismail, T. T. Teng and A. Z. Abdullah, Environ. Prot. Eng., 2012, 38, 119-131.

[93] T. Liu, Z.-L. Wang, X. Yan and B. Zhang, Chem. Eng. J., 2014, 245, 34-40.

[94] Ç. Üzüm, T. Shahwan, A. E. Eroğlu, I. Lieberwirth, T. B. Scott and K. R. Hallam, Chem. Eng. J., 2008,

144, 213-220.

[95] O. Çelebi, Ç. Üzüm, T. Shahwan and H. N. Erten, J. Hazard. Mater., 2007, 148, 761-767.

[96] N. Kržišnik, A. Mladenovič, A. S. Škapin, L. Škrlep, J. Ščančar and R. Milačič, Sci. Total Environ., 2014, 476-477, 20-28.

[97] T. B. Scott, I. C. Popescu, R. A. Crane and C. Noubactep, J. Hazard. Mater., 2011, 186, 280-287.

[98] T. Liu, X. Yang, Z. L. Wang and X. Yan, Water Res., 2013, 47, 6691-6700.

[99] P. Huang, Z. Ye, W. Xie, Q. Chen, J. Li, Z. Xu and M. Yao, Water Res., 2013, 47, 4050-4058.

[100] M. Dickinson and T. B. Scott, J. Hazard. Mater., 2010, 178, 171-179.

[101] S. C. N. Tang and I. M. C. Lo, Water Res., 2013, 47, 2613-2632.

[102] C. T. Yavuz, J. T. Mayo, W. W. Yu, A. Prakash, J. C. Falkner, S. Yean, L. Cong, H. J. Shipley, A. Kan, M. Tomson, D. Natelson and V. L. Colvin, Science, 2006, 314, 964-967.

[103] J. T. Mayo, C. Yavuz, S. Yean, L. Cong, H. Shipley, W. Yu, J. Falkner, A. Kan, M. Tomson and V. L. Colvin, Sci. Technol. Adv. Mater., 2007, 8, 71-75.

[104] C. T. Yavuz, J. T. Mayo, C. Suchecki, J. Wang, A. Z. Ellsworth, H. D'Couto, E. Quevedo, A. Prakash, L. Gonzalez, C. Nguyen, C. Kelty and V. L. Colvin, Environ. Geochem. Health, 2010, 32, 327-334.

[105] K. Simeonidis, T. Gkinis, S. Tresintsi, C. Martinez-Boubeta, G. Vourlias, I. Tsiaoussis, G.

Stavropoulos, M. Mitrakas and M. Angelakeris, Chem. Eng. J., 2011, 168, 1008-1015.

[106] Z. Bujňáková, P. Baláž, A. Zorkovská, M. J. Sayagués, J. Kováč and M. Timko, J. Hazard. Mater., 2013, 262, 1204-1212.

[107] H. J. Shipley, S. Yean, A. T. Kan and M. B. Tomson, Environ. Toxicol. Chem., 2009, 28, 509-515.

[108] H. J. Shipley, S. Yean, A. T. Kan and M. B. Tomson, Environ. Sci. Pollut. Res., 2010, 17, 1053-1062.

[109] S. Luther, N. Borgfeld, J. Kim and J. G. Parsons, Microchem. J., 2012, 101, 30-36.

[110] S. R. Chowdhury, E. K. Yanful and A. R. Pratt, Environ. Earth Sci., 2011, 64, 411-423.

[111] A. Khodabakhshi, M. M. Amin and M. Mozaffari, J. Environ. Heal. Sci. Eng., 2011, 8, 189-200.

[112] S. R. Chowdhury and E. K. Yanful, J. Environ. Manage., 2010, 91, 2238-2247.

[113] X. Luo, C. Wang, S. Luo, R. Dong, X. Tu and G. Zeng, Chem. Eng. J., 2012, 187, 45-52.

[114] Y. Jin, F. Liu, M. Tong and Y. Hou, J. Hazard. Mater., 2012, 227-228, 461-468.

[115] B. An, Q. Liang and D. Zhao, Water Res., 2011, 45, 1961-1972.

[116] L. Feng, M. Cao, X. Ma, Y. Zhu and C. Hu, J. Hazard. Mater., 2012, 217-218, 439-446.

[117] R. Chen, C. Zhi, H. Yang, Y. Bando, Z. Zhang, N. Sugiur and D. Golberg, J. Colloid Interface Sci., 2011, 359, 261-268.

[118] T. Türk and I. Alp, J. Ind. Eng. Chem., 2014, 20, 732-738.

[119] A. K. Mishra and S. Ramaprabhu, J. Phys. Chem. C, 2010, 114, 2583-2590.

[120] S. Hokkanen, E. Repo, S. Lou and M. Sillanpää, Chem. Eng. J., 2015, 260, 886-894.

[121] S. Lunge, S. Singh and A. Sinha, J. Magn. Magn. Mater., 2014, 356, 21-31.

[122] I. Akin, G. Arslan, A. Tor, M. Ersoz and Y. Cengeloglu, J. Hazard. Mater., 2012, 235-236, 62-68.

[123] T. Tuutijärvi, J. Lu, M. Sillanpää and G. Chen, J. Hazard. Mater., 2009, 166, 1415-1420.

[124] H. Park, N. V. Myung, H. Jung and H. Choi, J. Nanopart. Res., 2009, 11, 1981-1989.

[125] M. Auffan, J. Rose, O. Proux, D. Borschneck, A. Masion, P. Chaurand, J. L. Hazemann, C. Chaneac, J. P. Jolivet, M. R. Wiesner, A. Van Geen and J. Y. Bottero, Langmuir, 2008, 24, 3215-3222.

[126] T. Tuutijärvi, R. Vahala, M. Sillanpää and G. Chen, Environ. Technol., 2012, 33, 1927-1936.

[127] K. Simeonidis, E. Kaprara, T. Samaras, M. Angelakeris, N. Pliatsikas, G. Vourlias, M. Mitrakas and N. Andritsos, Sci. Total Environ., DOI:10.1016/j.scitotenv.2015.04.033

[128] J. Hu, I. M. C. Lo and G. Chen, Water Sci. Technol., 2004, 50, 139-146. 
[129] S. R. Chowdhury, E. K. Yanful and A. R. Pratt, J. Hazard. Mater., 2012, 235-236, 246-256.

[130] K. L. Dubrawski, C. M. van Genuchten, C. Delaire, S. E. Amrose, A. J. Gadgil and M. Mohseni, Environ. Sci. Technol., 2015, 49, 2171-2179.

[131] W. Jiang, M. Pelaez, D. D. Dionysiou, M. H. Entezari, D. Tsoutsou and K. O'Shea, Chem. Eng. J., 2013, 222, 527-533.

[132] J. Hu, G. Chen and I. M. C. Lo, Water Res., 2005, 39, 4528-4536.

[133] D. E. Crean, V. S. Coker, G. Van Der Laan and J. R. Lloyd, Environ. Sci. Technol., 2012, 46, 33523359.

[134] N. D. Telling, V. S. Coker, R. S. Cutting, G. Van Der Laan, C. I. Pearce, R. A. D. Pattrick, E. Arenholz and J. R. Lloyd, Appl. Phys. Lett., 2009, 95, 163701.

[135] N. N. Thinh, P. T. B. Hanh, L. T. T. Ha, L. N. Anh, T. V. Hoang, V. D. Hoang, L. H. Dang, N. Van Khoi and T. D. Lam, Mater. Sci. Eng. C, 2013, 33, 1214-1218.

[136] X. Liu, Q. Hu, Z. Fang, X. Zhang and B. Zhang, Langmuir, 2009, 25, 3-8.

[137] W. Jiang, Q. Cai, W. Xu, M. Yang, Y. Cai, D. D. Dionysiou and K. E. O’Shea, Environ. Sci. Technol., 2014, 48, 8078-8085.

[138] A. Nematollahzadeh, S. Seraj and B. Mirzayi, Chem. Eng. J., 2015, 277, 21-29.

[139] J. Hu, I. M. C. Lo and G. Chen, Sep. Purif. Technol., 2007, 58, 76-82.

[140] P. Yuan, M. Fan, D. Yang, H. He, D. Liu, A. Yuan, J. Zhu and T. Chen, J. Hazard. Mater., 2009, 166, 821-829.

[141] P. Yuan, D. Liu, M. Fan, D. Yang, R. Zhu, F. Ge, J. Zhu and H. He, J. Hazard. Mater., 2010, 173, 614-621.

[142] C. Wu, J. Fan, J. Jiang and J. Wang, RSC Adv., 2015, 5, 47165-47173.

[143] L. Wang, J. Li, Q. Jiang and L. Zhao, Dalton Trans., 2012, 41, 4544.

[144] H. A. Wiatrowski, S. Das, R. Kukkadapu, E. S. Ilton, T. Barkay and N. Yee, Environ. Sci. Technol., 2009, 43, 5307-5313.

[145] T. S. Pasakarnis, M. I. Boyanov, K. M. Kemner, B. Mishra, E. J. O’Loughlin, G. Parkin and M. M. Scherer, Environ. Sci. Technol., 2013, 47, 6987-6994.

[146] D. M. Singer, S. M. Chatman, E. S. Ilton, K. M. Rosso, J. F. Banfield and G. A. Waychunas, Environ. Sci. Technol., 2012, 46, 3821-3830.

[147] R. L. D. A. Loyo, S. I. Nikitenko, A. C. Scheinost and M. Simonoff, Environ. Sci. Technol., 2008, 42, 2451-2456.

[148] S. H. Huang and D. H. Chen, J. Hazard. Mater., 2009, 163, 174-179.

[149] J. Wang, S. Zheng, Y. Shao, J. Liu, Z. Xu and D. Zhu, J. Colloid Interf. Sci., 2010, 349, 293-299.

[150] Y.-M. Hao, C. Man and Z.-B. Hu, J. Hazard. Mater., 2010, 184, 392-399.

[151] A. Z. M. Badruddoza, A. S. H. Tay, P. Y. Tan, K. Hidajat and M. S. Uddin, J. Hazard. Mater., 2011, 185, 1177-1186.

[152] F. Ge, M.-M. Li, H. Ye and B.-X. Zhao, J. Hazard. Mater., 2012, 211-212, 366-372.

[153] A. R. Mahdavian and M. A. S. Mirrahimi, Chem. Eng. J., 2010, 159, 264-271.

[154] M. Bhaumik, A. Maity, V. V. Srinivasu and M. S. Onyango, J. Hazard. Mater., 2011, 190, 381-390.

[155] F.-L. Fan, Z. Qin, J. Bai, W.-D. Rong, F.-Y. Fan, W. Tian, X.-L. Wu, Y. Wang and L. Zhao, J. Environ.

Radioact., 2012, 106, 40-46.

[156] O. Hakami, Y. Zhang and C. J. Banks, Water Res., 2012, 46, 3913-3922.

[157] J. Liu, Z. Zhao and G. Jiang, Environ. Sci. Technol., 2008, 42, 6949-6954.

[158] A. Afkhami and R. Norooz-Asl, Colloid. Surface A., 2009, 346, 52-57.

[159] A. Roy and J. Bhattacharya, Chem. Eng. J., 2012, 211-212, 493-500.

[160] N. C. Feitoza, T. D. Gonçalves, J. J. Mesquita, J. S. Menegucci, M. K. M. S. Santos, J. A. Chaker, R. B. Cunha, A. M. M. Medeiros, J. C. Rubim and M. H. Sousa, J. Hazard. Mater., 2014, 264, 153-160.

[161] J. Hu, G. Chen and I. M. C. Lo, J. Environ. Eng., 2006, 132, 709-715.

[162] J. Song, H. Kong and J. Jang, J. Colloid Interf. Sci., 2011, 359, 505-511.

[163] S. R. Chowdhury and E. K. Yanful, J. Environ. Manage., 2013, 129, 642-651.

[164] N. Jordan, A. Ritter, A. C. Scheinost, S. Weiss, D. Schild and R. Hübner, Environ. Sci. Technol., 2014, 48, 1665-1674.

[165] N. Jordan, A. Ritter, H. Foerstendorf, A. C. Scheinost, S. Weiß, K. Heim, J. Grenzer, A. Mücklich and H. Reuther, Geochim. Cosmochim. Acta, 2013, 103, 63-75.

[166] Y. Feng, J.-L. Gong, G.-M. Zeng, Q.-Y. Niu, H.-Y. Zhang, C.-G. Niu, J.-H. Deng and M. Yan, Chem. Eng. J., 2010, 162, 487-494. 
[167] S. Garcia, S. Sardar, S. Maldonado, V. Garcia, C. Tamez and J. G. Parsons, Microchem. J., 2014, 117, 52-60.

[168] Y. Meng, D. Chen, Y. Sun, D. Jiao, D. Zeng and Z. Liu, Appl. Surf. Sci., 2015, 324, 745-750.

[169] J. Hu, I. M. C. Lo and G. Chen, Langmuir, 2005, 21, 11173-11179.

[170] J. Hu, I. M. C. Lo and G. Chen, Sep. Purif. Technol., 2007, 56, 249-256.

[171] V. Srivastava, Y. C. Sharma and M. Sillanpää, Appl. Surf. Sci., 2015, 338, 42-54.

[172] W. Tang, Y. Su, Q. Li, S. Gao and J. K. Shang, Water Res., 2013, 47, 3624-3634.

[173] A. Meidanchi and O. Akhavan, Carbon N. Y., 2014, 69, 230-238.

[174] A. Dey, R. Singh and M. K. Purkait, J. Water Process Eng., 2014, 3, 1-9.

[175] N. D. Phu, P. C. Phong, N. Chau, N. H. Luong, L. H. Hoang and N. H. Hai, J. Exp. Nanosci., 2009, 4, 253-258.

[176] W. Sun, W. Pan, F. Wang and N. Xu, Chem. Eng. J., 2015, 273, 353-362.

[177] V. A. Grover, J. Hu, K. E. Engates and H. J. Shipley, Environ. Toxicol. Chem., 2012, 31, 86-92.

[178] J. Ha, T. P. Trainor, F. Farges and G. E. Brown, Langmuir, 2009, 25, 5574-5585.

[179] H. Zeng, A. Singh, S. Basak, K. U. Ulrich, M. Sahu, P. Biswas, J. G. Catalano and D. E. Giammar, Environ. Sci. Technol., 2009, 43, 1373-1378.

[180] H. J. Shipley, K. E. Engates and A. M. Guettner, J. Nanopart. Res., 2010, 13, 2387-2397.

[181] J. S. Kwon, S. T. Yun, J. H. Lee, S. O. Kim and H. Y. Jo, J. Hazard. Mater., 2010, 174, 307-313.

[182] M. A. Ahmed, S. M. Ali, S. I. El-Dek and A. Galal, Mater. Sci. Eng. B Solid-State Mater. Adv.

Technol., 2013, 178, 744-751.

[183] C. Shan, Z. Ma and M. Tong, J. Hazard. Mater., 2014, 268, 229-236.

[184] K. Henke, Arsenic: Environmental Chemistry, Health Threats and Waste Treatment, John Wiley \& Sons, West Sussex, United Kingdom (2009).

[185] M. K. Ghosh, G. E. J. Poinern, T. B. Issa and P. Singh, Korean J. Chem. Eng., 2012, 29, 95-102.

[186] A. Manasse and C. Viti, Environ. Geol., 2007, 52, 1365-1374.

[187] K. Matis and A. Zouboulis, Water. Air. Soil Pollut., 1999, 297-316.

[188] M. Mohapatra and S. Anand, Int. J. Eng. Sci. Technol., 2010, 2, 127-146.

[189] B. Pan, H. Qiu, B. Pan, G. Nie, L. Xiao, L. Lv, W. Zhang, Q. Zhang and S. Zheng, Water Res., 2010, 44, 815-824.

[190] S. Dong, X. Dou, D. Mohan, C. U. Pittman Jr. and J. Luo, Chem. Eng. J., 2015, 270, 205-214.

[191] S. Tresintsi, K. Simeonidis, G. Vourlias, G. Stavropoulos and M. Mitrakas, Water Res., 2012, 46, 5255-5267.

[192] S. Tresintsi, K. Simeonidis, S. Estradé, C. Martinez-Boubeta, G. Vourlias, F. Pinakidou, M.

Katsikini, E. C. Paloura, G. Stavropoulos and M. Mitrakas, Environ. Sci. Technol., 2013, 47, 9699-9705.

[193] S. Tresintsi, K. Simeonidis and M. Mitrakas, Chem. Eng. J., 2014, 251, 192-198.

[194] http://www.infimet.com/

[195] S. Tresintsi, K. Simeonidis, N. Pliatsikas, G. Vourlias, P. Patsalas and M. Mitrakas, J. Solid State Chem., 2014, 213, 145-151.

[196] E. Kokkinos, K. Simeonidis, A. Zouboulis and M. Mitrakas, Desalin. Water Treat., 2014, 54, 2082 2090.

[197] V. Dimiropoulos, I.A. Katsoyiannis, A.I. Zouboulis, F. Noli, K. Simeonidis and M. Mitrakas, J. Water Process Eng., 2015, 7, 227-236.

[198] H. Y. Jeong, B. Klaue, J. D. Blum and K. F. Hayes, Environ. Sci. Technol., 2007, 41, 7699-7705.

[199] J. Liu, K. T. Valsaraj, I. Devai and R. D. DeLaune, J. Hazard. Mater., 2008, 157, 432-440.

[200] Z. Xiong, F. He, D. Zhao and M. O. Barnett, Water Res., 2009, 43, 5171-5179.

[201] T. Arakaki and J. W. Morse, Geochim. Cosmochim. Acta, 1993, 57, 9-14.

[202] A. Criscuoli, S. Majumdar, A. Figoli, G. C. Sahoo, P. Bafaro, S. Bandyopadhyay and E. Drioli, J. Hazard. Mater., 2012, 211-212, 281-287.

[203] Z. Zhao, J. Liu, F. Cui, H. Feng and L. Zhang, J. Mater. Chem., 2012, 22, 9052-9057.

[204] D. Nguyen Thanh, M. Singh, P. Ulbrich, N. Strnadova and F. Štěpánek, Sep. Purif. Technol., 2011, 82, 93-101.

[205] S. Y. Lee and S.-J. Park, J. Ind. Eng. Chem., 2013, 19, 1761.

[206] R. K. Upadhyay, N. Soin and S. S. Roy, RSC Adv., 2014, 4, 3823.

[207] J. Kim and B. V. der Bruggen, Environ. Pollut., 2010, 158, 2335.

[208] M. E. Pena, G. P. Korfiatis, M. Patel, L. Lippincott and X. Meng, Water Res., 2005, 39, 2327. 
[209] G. Jegadeesan, S. R. Al-Abed, V. Sundaram, H. Choi, K. G. Scheckel and D. D. Dionysiou, Water Res., 2010, 44, 965-973.

[210] Z. O. Kocabas-Atakli and Y. Yurum, Chem. Eng. J., 2013, 225, 625.

[211] D. Nabi, I. Aslam and I. A. Qazi, J. Environ. Sci., 2009, 21, 402-408.

[212] Z. Xu and X. Meng, J. Hazard. Mater., 2009, 168, 747-752.

[213] L. Yu, X. Peng, F. Ni, J. Li, D. Wang and Z. Luan, J. Hazard. Mater., 2013, 246-247, 10-17.

[214] C. Y. Jing, X. G. Meng, E. Calvache and G. B. Jiang, Environ. Pollut., 2009, 157, 2514-2519.

[215] H. Sun, X. Zhang, Q. Niu, Y. Chen and J. C. Crittenden, Water. Air. Soil Pollut., 2007, 178, 245254.

[216] H. Sun, X. Zhang, Z. Zhang, Y. Chen and J. C. Crittenden, Environ. Pollut., 2009, 157, 1165-1170.

[217] W. Ji, Y. Wang, I. Tanabe, X. Han, B. Zhao and Y. Ozaki, Chem. Sci., 2015, 6, 342.

[218] N. Zhang, H. Peng and B. Hu, Talanta, 2012, 94, 278.

[219] http://gravertech.com/pr_overview_metsorb.html

[220] http://www.dowwaterandprocess.com/en/Products/A/ADSORBSIA_AS600

[221] K. Hristovski, A. Baumgardner and P. Westerhoff, J. Hazard. Mater., 2007, 147, 265-274.

[222] K. Hristovski, P. Westerhoff and J. Crittenden, J. Hazard. Mater., 2008, 156, 604-611.

[223] K. Y. Kumar, H. B. Muralidhara, Y. A. Nayaka, J. Balasubramanyam and H. Hanumanthappa, Powder Technol., 2013, 246, 125-136.

[224] Y. Liu, Q. Li, S. Gao and J. K. Shang, J. Am. Ceram. Soc., 2011, 94, 217-223.

[225] X. Y. Yu, T. Luo, Y. Jia, Y. X. Zhang, J. H. Liu and X. J. Huang, J. Phys. Chem. C, 2011, 115, 2224222250.

[226] W. Liu, F. Huang, Y. Wang, T. Zou, J. Zheng and Z. Lin, Environ. Sci. Technol., 2011, 45, 19551961.

[227] A. R. Contreras, A. García, E. González, E. Casals, V. Puntes, A. Sánchez, X. Font and S. Recillas, Desalin. Water Treat., 2012, 41, 296-300.

[228] S. Recillas, A. García, E. González, E. Casals, V. Puntes, A. Sánchez and X. Font, Desalination, 2011, 277, 213-220.

[229] R. Li, Q. Li, S. Gao and J. K. Shang, Chem. Eng. J., 2012, 185-186, 127-135.

[230] W. Sun, Q. Li, S. Gao and J. K. Shang, Chem. Eng. J., 2012, 185-186, 136-143.

[231] K. Gupta, S. Bhattacharya, D. Chattopadhyay, A. Mukhopadhyay, H. Biswas, J. Dutta, N. R. Ray and U. C. Ghosh, Chem. Eng. J., 2011, 172, 219-229.

[232] X.-F. Yu, J.-W. Liu, H.-P. Cong, L. Xue, M. N. Arshad, H. A. Albar, T. R. Sobahi, Q. Gao and S.-H. Yu, Chem. Sci., 2015, 6, 2511-2515.

[233] W. Xu, J. Wang, L. Wang, G. Sheng, J. Liu, H. Yu and X. J. Huang, J. Hazard. Mater., 2013, 260, 498-507.

[234] http://www.zrpure.com/drinking-water/isolux_media.asp

[235] C. Hang, Q. Li, S. Gao and J. K. Shang, Ind. Eng. Chem. Res., 2012, 51, 353-361.

[236] H. Cui, Y. Su, Q. Li, S. Gao and J. K. Shang, Water Res., 2013, 47, 6258-6268.

[237] K. D. Hristovski, P. K. Westerhoff, J. C. Crittenden and L. W. Olson, Environ. Sci. Technol., 2008,

42, 3786-3790.

[238] L. Önnby, C. Svensson, L. Mbundi, R. Busquets, A. Cundy and H. Kirsebom, Sci. Total Environ., 2014, 473-474, 207-214.

[239] H. Ahmad, Y. Abbas, M. Hussain, N. Akhtar, T. Ansari, M. Zuber, K. Zia and S. Arain, Korean J. Chem. Eng., 2014, 31, 284-288.

[240] L. Önnby, P. S. Kumar, K. G. V Sigfridsson, O. F. Wendt, S. Carlson and H. Kirsebom, Chemosphere, 2014, 113, 151-157.

[241] K. J. Reddy, K. J. McDonald and H. King, J. Colloid Interf. Sci., 2013, 397, 96-102.

[242] A. Goswami, P. K. Raul and M. K. Purkait, Chem. Eng. Res. Des., 2012, 90, 1387-1396.

[243] C. A. Martinson and K. J. Reddy, J. Colloid Interf. Sci., 2009, 336, 406-411.

[244] K. P. Lisha, Anshup and T. Pradeep, Gold Bull., 2009, 42, 144.

[245] Y.-H. Lin and W.-L. Tseng, Anal. Chem., 2013, 82, 9194.

[246] L. Guerrini, I. Rodriguez-Loureiro, M. A. Correa-Duarte, Y. H. Lee, X. Y. Ling, F. J. Garcia de Abajo and R. A. Alvarez-Puebla, Nanoscale, 2014, 6, 8368.

[247] I. Ojea-Jimenez, X. Lopez, J. Arbiol and V. Puntes, ACS Nano, 2012, 6, 2253.

[248] L.-H. Jin and C.-S. Han, Sensor. Actuat. B-Chem., 2014, 195, 239. 
[249] S. Fernandes, C. M. Eichenseer, P. Kreitmeier, J. Rewitzer, V. Zlateski, R. N. Grass, W. J. Stark and O. Reiser, RSC Adv., 2015, 5, 46430-46436.

[250] H. Zhang, Q. Liu, T. Wang, Z. Yun, G. Li, J. Liu and G. Jiang, Anal. Chim. Acta, 2013, 770, 140.

[251] Q. Li, N. J. Easter and J. K. Shang, Environ. Sci. Technol., 2009, 43, 1534.

[252] M. A. Omole, I. O. K'Owino and O. A. Sadik, Appl. Catal. B Environ., 2007, 76, 158-167.

[253] Y. Chen, L. Wu, Y. Chen, N. Bi, X. Zheng, H. Qi, M. Qin, X. Liao, H. Zhang and Y. Tian, Microchim Acta, 2012, 177, 341-348.

[254] C. Jiang, Z. Guan, S. Y. Rachel Lim, L. Polavarapu and Q.-H. Xu, Nanoscale, 2011, 3, 3316-3320.

[255] J. Li, L. Chen, T. Lou and Y. Wang, ACS Appl. Mater. Interfaces, 2011, 3, 3936-3941.

[256] M. Liu, Z. Wang, S. Zong, H. Chen, D. Zhu, L. Wu, G. Hu and Y. Cui, ACS Appl. Mater. Interfaces, 2014, 6, 7371-7379.

[257] L. Polavarapu, J. Perez-Juste, Q.-H. Xu and L. M. Liz-Marzan, J. Mater. Chem. C, 2014, 2, 74607476.

[258] E. Sumesh, M. S. Bootharaju, Anshup and T. Pradeep, J. Hazard. Mater., 2011, 189, 450-457.

[259] Y. Wang, F. Yang and X. Yang, ACS Appl. Mater. Interfaces, 2010, 2, 339-342.

[260] Z.-H. Wu, J.-H. Lin and W.-L. Tseng, Biosens. Bioelectron., 2012, 34, 185-190.

[261] S. Bothra, J. N. Solanki and S. K. Sahoo, Sens. Actuat. B-Chem., 2013, 188, 937-943.

[262] T. Yordanova, P. Vasileva, I. Karadjova and D. Nihtianova, Analyst, 2014, 139, 1532-1540.

[263] A. Herman and A. P. Herman, J. Nanosci. Nanotechnol., 2014, 14, 946-957.

[264] Q. Li, S. Mahendra, D. Y. Lyon, L. Brunet, M. V. Liga, D. Li and P. J. J. Alvarez, Water Res., 2008, 42, 4591-4602.

[265] H. Schwegmann and F. H. Frimmel, in Nanoparticles in the Water Cycle: Properties, Analysis and Environmental Relevance, 2010, 165-182.

[266] N. von Moos and V. I. Slaveykova, Nanotoxicology, 2014, 8, 605-30.

[267] W.-R. Li, X.-B. Xie, Q.-S. Shi, H.-Y. Zeng, Y.-S. Ou-Yang and Y.-B. Chen, Appl Microbiol Biotechnol, 2010, 85, 1115-1122.

[268] R. Kaegi, A. Voegelin, B. Sinnet, S. Zuleeg, H. Hagendorfer, M. Burkhardt and H. Siegrist, Environ. Sci. Technol., 2011, 45, 3902-3908.

[269] M. Rai, A. Yadav and A. Gade, Biotechnol. Adv., 2009, 27, 76-83.

[270] Q. Bao, D. Zhang and P. Qi, J. Colloid Interf. Sci., 2011, 360, 463-470.

[271] S. Agnihotri, S. Mukherji and S. Mukherji, RSC Adv., 2014, 4, 3974-3983.

[272] Z. Wang, T. Xia and S. Liu, Nanoscale, 2015, 7, 7470-7481.

[273] S. Pal, Y. K. Tak and J. M. Song, Appl. Environ. Microbiol., 2007, 73, 1712-1720.

[274] A. J. Kora and R. B. Sashidhar, J. Antibiot., 2015, 68, 88-97.

[275] M. Ahamed, M. Karns, M. Goodson, J. Rowe, S. M. Hussain, J. J. Schlager and Y. L. Hong, Toxicol. Appl. Pharmacol., 2008, 233, 404-410.

[276] L. Cui, P. Y. Chen, S. D. Chen, Z. H. Yuan, C. P. Yu, B. Ren and K. S. Zhang, Anal. Chem., 2013, 85, 5436-5443.

[277] T. Hennebel, B. De Gusseme, N. Boon and W. Verstraete, Trends Biotechnol., 2009, 27, 90-98.

[278] J. S. Kim, E. Kuk, K. N. Yu, J.-H. Kim, S. J. Park, H. J. Lee, S. H. Kim, Y. K. Park, Y. H. Park, C.-Y.

Hwang, Y.-K. Kim, Y.-S. Lee, D. H. Jeong and M.-H. Cho, Nanomedicine, 2007, 3, 95-101.

[279] M. U. Sankar, S. Aigal, S. M. Maliyekkal, A. Chaudhary, Anshup, A. A. Kumar, K. Chaudhari and T. Pradeep, Proc. Natl. Acad. Sci. USA, 2013, 110, 8459-8464.

[280] T. Pradeep and Anshup, Thin Solid Films, 2009, 517, 6441-6478.

[281] M. Ahamed, M. S. AlSalhi and M. K. J. Siddiqui, Clin. Chim. Acta, 2010, 411, 1841-1848.

[282] V. S. Srivastava, Arch. Appl. Sci. Res., 2010, 2, 82.

[283] M. T. Amin, A. A. Alazba and U. Manzoor, Adv. Mater. Sci. Eng., 2014, 2014, Article ID: 825910

[284] T. A. Dankovich and J. A. Smith, Water Res., 2014, 63, 245-251.

[285] M. Ben-Sasson, X. Lu, E. Bar-Zeev, K. R. Zodrow, S. Nejati, G. Qi, E. P. Giannelis and M. Elimelech, Water Res., 2014, 62, 260-270.

[286] W.-L. Chou, D.-G. Yu and M.-C. Yang, Polym. Advan. Technol.., 2005, 16, 600-607.

[287] C. A. Mecha and V. L. Pillay, J. Memb. Sci., 2014, 458, 149-156.

[288] Y. Lv, H. Liu, Z. Wang, S. Liu, L. Hao, Y. Sang, D. Liu, J. Wang and R. I. Boughton, J. Memb. Sci., 2009, 331, 50-56.

[289] R. Bandyopadhyaya, M. V. Sivaiah and P. A. Shankar, J. Chem. Technol. Biotechnol., 2008, 83, 1177-1180. 
[290] T. A. Dankovich, Environ. Sci. Nano, 2014, 1, 367-378.

[291] V. A. Oyanedel-Craver and J. A. Smith, Environ. Sci. Technol., 2008, 42, 927-933.

[292] D. He, M. Kacopieros, A. Ikeda-Ohno and T. D. Waite, Environ. Sci. Technol., 2014, 48, 1232012326.

[293] B. Ehdaie, C. Krause and J. A. Smith, Environ. Sci. Technol., 2014, 48, 13901-13908.

[294] T. A. Dankovich and D. G. Gray, Environ. Sci. Technol., 2011, 45, 1992-1998.

[295] P. Jain and T. Pradeep, Biotechnol. Bioeng., 2005, 90, 59-63.

[296] V. Apalangya, V. Rangari, B. Tiimob, S. Jeelani and T. Samuel, Appl. Surf. Sci., 2014, 295, 108-114. [297] Y. J. Xiong, M. Brunson, J. Huh, A. R. Huang, A. Coster, K. Wendt, J. Fay and D. Qin, Small, 2013, 9, 2628-2638.

[298] H. Zhang, J. A. Smith and V. Oyanedel-Craver, Water Res., 2012, 46, 691-699.

[299] M. V. D. Z. Park, A. M. Neigh, J. P. Vermeulen, L. J. J. de la Fonteyne, H. W. Verharen, J. J. Briedé, H. van Loveren and W. H. de Jong, Biomaterials, 2011, 32, 9810-9817.

[300] D. Gangadharan, K. Harshvardan, G. Gnanasekar, D. Dixit, K. M. Popat and P. S. Anand, Water Res., 2010, 44, 5481-5487.

[301] R. Bryaskova, N. Georgieva, D. Pencheva, Z. Todorova, N. Lazarova and T. Kantardjiev, Colloid. Surface A.., 2014, 444, 114-119.

[302] Y. Seo, J. Hwang, J. Kim, Y. Jeong, M. P. Hwang and J. Choi, Int. J. Nanomed., 2014, 9, 4621-4629.

[303] N. Savage and M. Diallo, J. Nanopart. Res., 2005, 7, 331-342.

[304] Z. Xiong, J. Ma, W. J. Ng, T. D. Waite and X. S. Zhao, Water Res., 2011, 45, 2095-2103.

[305] V. R. Ravisankar and A. B. Januna at 'Science against microbial pathogens: communicating current research ad technological advances' edited by A. Mendez-Vilas, Formatex Research Center, Badajoz, Spain (2011).

[306] W. He, H.-K. Kim, W. G. Wamer, D. Melka, J. H. Callahan and J.-J. Yin, J. Am. Chem. Soc., 2014, 136, 750.

[307] S. K. Das, A. R. Das and A. K. Guha, Langmuir, 2009, 25, 8192.

[308] D. Prasad, Shankaracharya and A. S. Vidyarthi, World J. Microbiol. Biotechnol., 2011, 27, 2227.

[309] C. Li, R. Younesi, Y. Cai, Y. Zhu, M. Ma and J. Zhu, Appl. Catal. B-Environ., 2014, 156-157, 314.

[310] D. M. A. Alrousan, P. S. M. Dunlop, T. A. McMurray and J. A. Byrne, Water Res., 2009, 43, 47.

[311] X. Lin, J. Li, S. Ma, G. Liu, K. Yang, M. Tong and D. Lin, PLOS ONE, 2014, 9, e110247.

[312] M. V. Liga, S. J. Maguire-Boyle, H. R. Jafry, A. R. Barron and Q. Li, Environ. Sci. Technol., 2013, 47, 6463.

[313] I. Chauhan and P. Mohanty, Cellulose, 2015, 22, 507.

[314] R. Bergamasco, F. V. da Silva, F. S. Arakawa, N. U. Yamaguchi, M. H. M. Reis, C. J. Tavares, M. T. P. S. de Amorim and C. R. G. Tavares, Chem. Eng. J., 2011, 174, 102-109.

[315] M. V. Liga, E. L. Bryant, V. L. Colvin and Q. Li, Water Res., 2011, 45, 535.

[316] G. Xiao, X. Zhang, W. Zhang, S. Zhang, H. Su and T. Tan, Appl. Catal. B-Environ., 2015, 170-171, 255.

[317] M. Li, M. E. Noriega-Trevino, N. Nino-Martinez, C. Marambio-Jones, J. Wang, R. Damoiseaux, F. Ruiz and E. M. V. Hoek, Environ. Sci. Technol., 2011, 45, 8989.

[318] H. Younas, I. A. Qazi, I. Hashmi, M. A. Awan, A. Mahmood and H. A. Qayyum, Environ. Sci. Pollut. Res., 2014, 21, 740.

[319] R. Liu, H. S. Wu, R. Yeh, C. Y. Lee and Y. Hung, Int. J. Photoenergy, 2012, 2012, 640487.

[320] I. Altin and M. Sokmen, Water Air Soil Pollut., 2014, 225, 1786.

[321] M. Auffan, W. Achouak, J. Rose, M. A. Roncato, C. Chanéac, D. T. Waite, A. Masion, J. C. Woicik, M. R. Wiesner and J. Y. Bottero, Environ. Sci. Technol., 2008, 42, 6730-6735.

[322] J. Chen, Z. Xiu, G. V. Lowry and P. J. J. Alvarez, Water Res., 2011, 45, 1995-2001.

[323] M. Diao and M. Yao, Water Res., 2009, 43, 5243-5251.

[324] A. Sevcu, Y. S. El-Temsah, E. J. Joner and M. Cernik, Microbes Environ., 2011, 26, 271-281.

[325] C. Lee, J. Y. Kim, W. II Lee, K. L. Nelson, J. Yoon and D. L. Sedlak, Environ. Sci. Technol., 2008, 42, 4927-4933.

[326] J. Y. Kim, C. Lee, D. C. Love, D. L. Sedlak, J. Yoon and K. L. Nelson, Environ. Sci. Technol., 2011, 45, 6978-6984.

[327] R. J. Barnes, C. J. van der Gast, O. Riba, L. E. Lehtovirta, J. I. Prosser, P. J. Dobson and I. P. Thompson, J. Hazard. Mater., 2010, 184, 73-80. 
[328] Z. Li, K. Greden, P. J. J. Alvarez, K. B. Gregory and G. V. Lowry, Environ. Sci. Technol., 2010, 44, 3462-3467.

[329] N. Tran, A. Mir, D. Mallik, A. Sinha, S. Nayar and T. J. Webster, Int. J. Nanomed., 2010, 5, 277283.

[330] W. Zhang, B. Rittmann and Y. Chen, Environ. Sci. Technol., 2011, 45, 2172-2178.

[331] S. Singh, K. C. Barick and D. Bahadur, J. Hazard. Mater., 2011, 192, 1539-1547.

[332] D. Das, B. C. Nath, P. Phukon and S. K. Dolui, Colloid. Surface. B, 2013, 101, 430-433.

[333] A. Azam, A. S. Ahmed, M. Oves, M. S. Khan and A. Memic, Int. J. Nanomed., 2012, 7, 3527-3535.

[334] V. V. T. Padil and M. Černík, Int. J. Nanomed., 2013, 8, 889-898.

[335] T. Jin and Y. He, J. Nanopart. Res., 2011, 13, 6877-6885.

[336] L. Huang, D. Q. Li, Y. J. Lin, M. Wei, D. G. Evans and X. Duan, J. Inorg. Biochem., 2005, 99, 986993.

[337] S. Ravikumar, R. Gokulakrishnan and P. Boomi, Asian Pacific J. Trop. Dis., 2012, 2, 85-89.

338 Y. J. Lin, D. Q. Li, G. Wang, L. Huang and X. Duan, J. Mater. Sci. Mater. Med., 2005, 16, 53-56.

[339] P. K. Stoimenov, R. L. Klinger, G. L. Marchin and K. J. Klabunde, Langmuir, 2002, 18, 6679-6686.

[340] P. J. P. Espitia, N. F. F. Soares, J. S. R. Coimbra, N. J. de Andrade, R. S. Cruz and E. A. A. Medeiros, Food Bioprocess Tech.., 2012, 5, 1447-1464.

[341] A. Azam, A. S. Ahmed, M. Oves, M. S. Khan, S. S. Habib and A. Memic, Int. J. Nanomed., 2012, 7, 6003-6009.

[342] R. Brayner, R. Ferrari-lliou, N. Brivois, S. Djediat, M. F. Benedetti and F. Fiévet, Nano Lett., 2006, 6, 866-870.

[343] R. Colonia, J. L. Solís and M. Gómez, Adv. Nat. Sci. Nanosci. Nanotechnol., 2013, 5, 015008.

[344] C. O. Dimkpa, J. E. McLean, D. W. Britt and A. J. Anderson, BioMetals, 2013, 26, 913-924.

[345] S. Gunalan, R. Sivaraj and V. Rajendran, Prog. Nat. Sci. Mater. Int., 2012, 22, 693-700.

[346] N. Padmavathy and R. Vijayaraghavan, Sci. Technol. Adv. Mater., 2008, 9, 035004.

[347] D. Sharma, J. Rajput, B. S. Kaith, M. Kaur and S. Sharma, Thin Solid Films, 2010, 519, 1224-1229.

[348] Y. Xie, Y. He, P. L. Irwin, T. Jin and X. Shi, Appl. Environ. Microbiol., 2011, 77, 2325-2331.

[349] L. He, Y. Liu, A. Mustapha and M. Lin, Microbiol. Res., 2010, 166, 207-215.

[350] A. Lipovsky, Y. Nitzan, A. Gedanken and R. Lubart, Nanotechnology, 2011, 22, 105101.

[351] S. Vlad, C. Tanase, D. Macocinschi, C. Ciobanu, T. Balaes, D. Filip, I. N. Gostin and L. M.

Gradinaru, Dig. J. Nanomater. Bios., 2012, 7, 51-58.

[352] K. Kairyte, A. Kadys and Z. Luksiene, J. Photochem. Photobiol. B Biol., 2013, 128, 78-84.

[353] S. Azizi, M. Ahmad, M. Mahdavi and S. Abdolmohammadi, BioResources, 2013, 8, 1841-1851.

[354] P. Gajjar, B. Pettee, D. W. Britt, W. Huang, W. P. Johnson and A. J. Anderson, J. Biol. Eng., 2009, 3, 9.

[355] M. Valodkar, P. S. Rathore, R. N. Jadeja, M. Thounaojam, R. V. Devkar and S. Thakore, J. Hazard. Mater., 2012, 201-202, 244-249.

[356] P. Kanhed, S. Birla, S. Gaikwad, A. Gade, A. B. Seabra, O. Rubilar, N. Duran and M. Rai, Mater. Lett., 2014, 115, 13-17.

[357] Y. Wei, S. Chen, B. Kowalczyk, S. Huda, T. P. Gray and B. A. Grzybowski, J. Phys. Chem. C, 2010, 114, 15612-15616.

[358] L. Esteban-Tejeda, F. Malpartida, A. Esteban-Cubillo, C. Pecharromán and J. S. Moya, Nanotechnology, 2009, 20, 505701.

[359] U. Bogdanović, V. Lazić, V. Vodnik, M. Budimir, Z. Marković and S. Dimitrijević, Mater. Lett., 2014, 128, 75-78.

[360] Q. Kang, Q. Z. Lu, S. H. Liu, L. X. Yang, L. F. Wen, S. L. Luo and Q. Y. Cai, Biomaterials, 2010, 31, 3317-3326.

[361] Y. Liu, J. Li, X. Qiu and C. Burda, J. Photochem. Photobiol. A Chem., 2007, 190, 94-100.

[362] Z. Marková, K. M. Šišková, J. Filip, J. Čuda, M. Kolář, K. Šafářová, I. Medřík and R. Zbořil, Environ. Sci. Technol., 2013, 47, 5285-5293.

[363] S. Y. Park, J. W. Chung, R. D. Priestley and S. Y. Kwak, Cellulose, 2012, 19, 2141-2151.

[364] J.-Q. Xue, D.-W. Li, L.-L. Qu and Y.-T. Long, Anal. Chim. Acta, 2013, 777, 57.

[365] A. S. Nair, R. T. Tom and T. Pradeep, J. Environ. Monit., 2003, 5, 363.

[366] A. S. Nair and T. Pradeep, J. Nanosci. Nanotechnol., 2007, 7, 1871-1877.

[367] M. S. Bootharaju and T. Pradeep, Langmuir, 2012, 28, 2671.

[368] C. Mondal, J. Pal, M. Ganguly, A. K. Sinha, J. Jana and T. Pal, New J. Chem., 2014, 38, 2999. 
[369] X. Wang, Y.-X. Wang, B. Yuan, H.-J. Cui and M.-L. Fu, RSC Adv., 2015, 5, 18806.

[370] M. S. Wong, P. J. J. Alvarez, Y.-I. Fang, N. Akcin, M. O. Nutt, J. T. Miller and K. N. Heck, J. Chem. Technol. Biotechnol., 2009, 84, 158.

[371] Y. Li, L. Qi, Y. Shen and H. Ma, Anal. Chim. Acta, 2014, 811, 36.

[372] Y. Su, A. S. Adeleye, Y. Huang, X. Sun, C. Dai, X. Zhou, Y. Zhang and A. A. Keller, Water Res., 2014, 63, 102.

[373] D.-Q. Zhang, T.-Y. Sun, X.-F. Yu, Y. Jia, M. Chen, J.-H. Wang, H. Huang and P. K. Chu, Mater. Res. Bull., 2014, 52, 122.

[374] R. Gupta and G. U. Kulkarni, ChemSusChem, 2011, 4, 737.

[375] H. Qian, L. A. Pretzer, J. C. Velazquez, Z. Zhao and M. S. Wong, J. Chem. Technol. Biotechnol., 2013, 88, 735.

[376] C. Wang and C. Yu, Rev. Anal. Chem., 2013, 32, 1.

[377] H. Dong, G. Zeng, L. Tang, C. Fan, C. Zhang, X. He and Y. He, Water Res., 2015, 79, 128-146.

[378] I. Ilisz, A. Dombi, K. Mogyorosi and I. Dekany, Colloid. Surface. A, 2004, 230, 89.

[379] M. Rastgar, A. R. Zolfaghari, H. R. Mortaheb, H. Sayahi and H. R. Naderi, J. Adv. Oxid. Technol., 2013, 16, 292.

[380] V. Vaiano, O. Sacco, D. Sannino and P. Ciambelli, Appl. Catal. B-Environ., 2015, 170-171, 153.

[381] S. Filice, D. D'Angelo, S. Libertino, I. Nicotera, V. Kosma, V. Privitera and S. Scalese, Carbon, 2015, 82, 489.

[382] A. Hu, R. Liang, X. Zhang, S. Kurdi, D. Luong, H. Huang, P. Peng, E. Marzbanrad, K. D. Oakes, Y. Zhou and M. R. Servos, J. Photoc. Photobio. A, 2013, 256, 7.

[383] X. Li, Y. Chen, X. Hu, Y. Zhang and L. Hu, J. Membrane Sci., 2014, 471, 118.

[384] A. M. Asiri, M. S. Al-Amoudi, S. A. Bazaid, A. A. Adam, K. A. Alamry and S. Anandan, J. Saudi Chem. Soc., 2014, 18, 155.

[385] R. Liang, A. Hu, W. Li and Y. N. Zhou, J. Nanopart. Res., 2013, 15, 1990.

[386] S. Murgolo, F. Petronella, R. Ciannarella, R. Comparelli, A. Agostiano, M. L. Curri and G. Mascolo, Catal. Today, 2015, 240, 114.

[387] V. S. Priya and L. Philip, Int. J. Env. Sci. Dev., 2015, 6, 286.

[388] J. Senthilnathan and L. Philip, Water Air Soil Pollut., 2010, 210, 143.

[389] P. Singla, M. Sharma, O. P. Pandey and K. Singh, Appl. Phys. A, 2014, 116, 371-378.

[390] F. U. Jian-Feng, J.I. Min and A. N. Ding-Nian, J. Environ. Sci., 2005, 17, 942.

[391] A. A. Abd Elrady, M. A. Salman Hassan and A. M. Kamal, Nanosci. Nanotechnol., 2013, 3, 90.

[392] M. J. Benotti, R. A. Trenholm, B. J. Vanderford, J. C. Holady, B. D. Stanford and S. A. Snyder, Environ. Sci. Technol., 2009, 43, 597.

[393] A. Hu, X. Zhang, K. D. Oakes, P. Peng, Y. N. Zhou and M. R. Servos, J. Hazard. Mater., 2011, 189, 278.

[394] A. Hu, X. Zhang, D. Luong, K. D. Oakes, M. R. Servos, R. Liang, S. Kurdi, P. Peng and Y. Zhou, Waste Biomass Valor., 2012, 3, 443.

[395] Water Treatment, Edited by W. Elshorbagy and R. K. Chowdhury, ISBN: 978-953-51-0928-0, Chapter 4: Waste Water Treatment Methods, Publisher: InTech, 2013.

[396] A. L. Giraldo, G. A. Penuela, R. A. Torres-Palma, N. J. Pino, R. A. Palominos and H. D. Mansilla, Water Res., 2010, 44, 5158.

[397] S. Lazaro-Navas, S. Prashar, M. Fajardo and S. Gomez-Ruiz, J. Nanopart. Res., 2015, 17, 94.

[398] T. I. Nkambule, A. T. Kuvarega, R. W. M. Krause, J. Haarhoff and B. B. Mamba, Environ. Sci. Pollut. Res., 2012, 19, 4120.

[399] J. Grzechulska and A. W. Morawski, Appl. Catal. B Environ., 2003, 46, 415-419.

[400] M. Lazar, S. Varghese and S. Nair, Catalysts, 2012, 2, 572-601.

[401] M. S. Vohra and K. Tanaka, Water Res., 2003, 37, 3992-3996.

[402] T. Tanaka, K. Teramura, T. Yamamoto, S. Takenaka, S. Yoshida and T. Funabiki, J. Photochem. Photobiol. A Chem., 2002, 148, 277-281.

[403] E. P. Reddy, L. Davydov and P. Smirniotis, Appl. Catal. B Environ., 2003, 42, 1-11.

[404] C. Ooka, H. Yoshida, M. Horio, K. Suzuki and T. Hattori, Appl. Catal. B Environ., 2003, 41, 313321.

[405] J. Araña, J. M. Doña-Rodríguez, E. Tello Rendón, C. Garriga I Cabo, O. González-Díaz, J. A. Herrera-Melián, J. Pérez-Peña, G. Colón and J. A. Navío, Appl. Catal. B Environ., 2003, 44, 161-172. [406] C. H. Ao and S. C. Lee, Appl. Catal. B Environ., 2003, 44, 191-205. 
[407] G. Balasubramanian, D. D. Dionysiou, M. T. Suidan, I. Baudin and J. M. Laîné, Appl. Catal. B Environ., 2004, 47, 73-84.

[408] N. Baram, D. Starosvetsky, J. Starosvetsky, M. Epshtein, R. Armon and Y. Ein-Eli, Electrochim. Acta, 2009, 54, 3381-3386.

[409] G. R. M. Echavia, F. Matzusawa and N. Negishi, Chemosphere, 2009, 76, 595-600.

[410] N. Miranda-García, S. Suárez, B. Sánchez, J. M. Coronado, S. Malato and M. I. Maldonado, Appl. Catal. B Environ., 2011, 103, 294-301.

[411] B. Tryba, J. Hazard. Mater., 2008, 151, 623-627.

[412] A. H. Fostier, M. do S. S. Pereira, S. Rath and J. R. Guimarães, Chemosphere, 2008, 72, 319-324.

[413] G. R. R. A. Kumara, F. M. Sultanbawa, V. P. S. Perera, I. R. M. Kottegoda and K. Tennakone, Sol. Energy Mater. Sol. Cells, 1999, 58, 167-171.

[414] J. C. Lee, M. S. Kim and B. W. Kim, Water Res., 2002, 36, 1776-1782.

[415] I.-H. Cho, J.-H. Park and Y.-G. Kim, J. Environ. Sci. Heal.A., 2005, 40, 1033-1044.

[416] J. Senthilnathan and L. Philip, J. Environ. Sci. Heal. B., 2009, 44, 262-270.

[417] R. van Grieken, J. Marugán, C. Sordo, P. Martínez and C. Pablos, Appl. Catal. B Environ., 2009, 93, 112-118.

[418] W. Zhang and D. W. Elliott, Remediat. J., 2006, 16, 7-21.

[419] Z. ming Xiu, Z. hui Jin, T. long Li, S. Mahendra, G. V. Lowry and P. J. J. Alvarez, BioresourceTechnol., 2010, 101, 1141-1146.

[420] L. Wu, M. Shamsuzzoha and S. M. C. Ritchie, J. Nanopart. Res., 2005, 7, 469-476.

[421] C. B. Wang and W. X. Zhang, Environ. Sci. Technol., 1997, 31, 2154-2156.

[422] H. Song and E. R. Carraway, Appl. Catal. B Environ., 2008, 78, 53-60.

[423] Y. Liu, T. Phenrat and G. V. Lowry, Environ. Sci. Technol., 2007, 41, 7881-7887.

[424] Y. Liu, S. A. Majetich, R. D. Tilton, D. S. Sholl and G. V. Lowry, Environ. Sci. Technol., 2005, 39, 1338-1345.

[425] R. J. Barnes, O. Riba, M. N. Gardner, A. C. Singer, S. A. Jackman and I. P. Thompson, Chemosphere, 2010, 80, 554-562.

[426] H. Kim, H. J. Hong, J. Jung, S. H. Kim and J. W. Yang, J. Hazard. Mater., 2010, 176, 1038-1043.

[427] M. Zhang, F. He, D. Zhao and X. Hao, Water Res., 2011, 45, 2401-2414.

[428] D. W. Elliott and W. X. Zhang, Environ. Sci. Technol., 2001, 35, 4922-4926.

[429] H. Tian, J. Li, Z. Mu, L. Li and Z. Hao, Sep. Purif. Technol., 2009, 66, 84-89.

[430] S. H. Joo and D. Zhao, Chemosphere, 2008, 70, 418-425.

[431] D. W. Elliott, H.-L. Lien and W.-X. Zhang, J. Environ. Eng., 2009, 135, 317-324.

[432] A. N. Bezbaruah, J. M. Thompson and B. J. Chisholm, J. Environ. Sci. Heal.B., 2009, 44, 518-524.

[433] Z. Xiong, D. Zhao and G. Pan, Water Res., 2007, 41, 3497-3505.

[434] R. Cheng, J. Wang and W. Zhang, Front. Environ. Sci. Eng. China, 2008, 2, 103-108.

[435] S. Machado, W. Stawiński, P. Slonina, A. R. Pinto, J. P. Grosso, H. P. A. Nouws, J. T. Albergaria

and C. Delerue-Matos, Sci. Total Environ., 2013, 461-462, 323-329.

[436] Y. T. Lin, C. H. Weng and F. Y. Chen, Sep. Purif. Technol., 2008, 64, 26-30.

[437] S. H. Joo, A. J. Feitz and T. D. Waite, Environ. Sci. Technol., 2004, 38, 2242-2247.

[438] C. Su, R. W. Puls, T. A. Krug, M. T. Watling, S. K. O’Hara, J. W. Quinn and N. E. Ruiz, Water Res., 2012, 46, 5071-5084.

[439] F. He, D. Zhao and C. Paul, Water Res., 2010, 44, 2360-2370.

[440] S. Ozcan, A. Tor and M. E. Aydin, J. AOAC Int., 2012, 95, 1343-1349.

[441] G. Guan, L. Yang, Q. Mei, K. Zhang, Z. Zhang and M. Y. Han, Anal. Chem., 2012, 84, 9492-9497.

[442] X. Zheng, L. He, Y. Duan, X. Jiang, G. Xiang, W. Zhao and S. Zhang, J. Chromatogr. A, 2014, 1358, 39-45.

[443] Z. He, P. Wang, D. Liu and Z. Zhou, Talanta, 2014, 127, 1-8.

[444] D. H. Chen and S. H. Huang, Process Biochem., 2004, 39, 2207-2211.

[445] H. Niu, D. Zhang, S. Zhang, X. Zhang, Z. Meng and Y. Cai, J. Hazard. Mater., 2011, 190, 559-565.

[446] X. Ge, W. Zhang, Y. Lin and D. Du, Biosens. Bioelectron., 2013, 50, 486-491.

[447] A. Z. M. Badruddoza, G. S. S. Hazel, K. Hidajat and M. S. Uddin, Colloid. Surface. A, 2010, 367, 85-95.

[448] G. R. Chaudhary, P. Saharan, A. Kumar, S. K. Mehta, S. Mor and A. Umar, J. Nanosci. Nanotechnol., 2013, 13, 3240-3246.

[449] X. Zhang, P. Zhang, Z. Wu, L. Zhang, G. Zeng and C. Zhou, Colloid. Surface. A, 2013, 435, 85-90. 
[450] F. Ge, H. Ye, M.-M. Li and B.-X. Zhao, Chem. Eng. J., 2012, 198-199, 11-17.

[451] Z. Zhou, S. Lin, T. Yue and T. C. Lee, J. Food Eng., 2014, 126, 133-141.

[452] M. H. Do, N. H. Phan, T. D. Nguyen, T. T. S. Pham, V. K. Nguyen, T. T. T. Vu and T. K. P. Nguyen, Chemosphere, 2011, 85, 1269-1276.

[453] Z. Zhang and J. Kong, J. Hazard. Mater., 2011, 193, 325-329.

[454] S. Qu, F. Huang, S. Yu, G. Chen and J. Kong, J. Hazard. Mater., 2008, 160, 643-647.

[455] A. Afkhami, M. Saber-Tehrani and H. Bagheri, Desalination, 2010, 263, 240-248.

[456] K. M. Paknikar, V. Nagpal, A. V. Pethkar and J. M. Rajwade, Sci. Technol. Adv. Mat., 2005, 6, 370374.

[457] D. Du, X. Ye, J. Zhang, Y. Zeng, H. Tu, A. Zhang and D. Liu, Electrochem. Commun., 2008, 10, 686690.

[458] G. Liu and Y. Lin, Anal. Chem., 2005, 77, 5894-5901.

[459] J. Fei, Y. Cui, X. Yan, W. Qi, Y. Yang, K. Wang, Q. He and J. Li, Adv. Mater., 2008, 20, 452-456.

[460] G. Moussavi and M. Mahmoudi, J. Hazard. Mater., 2009, 168, 806-812.

[461] R. Ullah and J. Dutta, J. Hazard. Mater., 2008, 156, 194-200.

[462] R. K. Upadhyay, M. Sharma, D. K. Singh, S. S. Amritphale and N. Chandra, Sep. Purif. Technol., 2012, 88, 39-45.

[463] T. M. Scown, R. van Aerle and C. R. Tyler, Crit. Rev. Toxicol., 2010, 40, 653-670.

[464] H. Weinberg, A. Galyean and M. Leopold, TrAC - Trends Anal. Chem., 2011, 30, 72-83.

[465] M. N. Moore, Environ. Int., 2006, 32, 967-976.

[466] R. Barrena, E. Casals, J. Colón, X. Font, A. Sánchez and V. Puntes, Chemosphere, 2009, 75, 850857.

[467] E. Navarro, A. Baun, R. Behra, N. B. Hartmann, J. Filser, A. J. Miao, A. Quigg, P. H. Santschi and L. Sigg, Ecotoxicology, 2008, 17, 372-386.

[468] E. J. Petersen, S. A. Diamond, A. J. Kennedy, G. G. Goss, K. Ho, J. Lead, S. K. Hanna, N. B. Hartmann, K. HundRinke, B. Mader, N. Manier, P. Pandard, E. R. Salinas, P. Sayre, Environ. Sci. Technol.,

doi:10.1021/acs.est.5b00997.

[469] K. Tiede, M. Hassellöv, E. Breitbarth, Q. Chaudhry and A. B. A. Boxall, J. Chromatogr. A, 2009, 1216, 503-509.

[470] A. Simon-Deckers, S. Loo, M. Mayne-L’Hermite, N. Herlin-Boime, N. Menguy, C. Reynaud, B. Gouget and M. Carriere, Environ. Sci. Technol., 2009, 43, 8423-8429.

[471] R. D. Handy, F. Von Der Kammer, J. R. Lead, M. Hassellöv, R. Owen and M. Crane, Ecotoxicology, 2008, 17, 287-314.

[472] N. Lewinski, V. Colvin and R. Drezek, Small, 2008, 4, 26-49.

[473] A. Albanese and W. C. W. Chan, ACS Nano, 2011, 5, 5478-5489.

[474] A. Menard, D. Drobne and A. Jemec, Environ. Pollut., 2011, 159, 677-684.

[475] K. Van Hoecke, K. A. C. De Schamphelaere, Z. Ali, F. Zhang, A. Elsaesser, P. Rivera-Gil, W. J. Parak, G. Smagghe, C. V. Howard and C. R. Janssen, Nanotoxicology, 2011, 1-11.

[476] B. Trouiller, R. Reliene, A. Westbrook, P. Solaimani and R. H. Schiestl, Cancer Res., 2009, 69, 8784-8789.

[477] Q. Fang, X. Shi, L. Zhang, Q. Wang, X. Wang, Y. Guo and B. Zhou, J. Hazard. Mater., 2015, 283, 897.

[478] T. E. A. Chalew, G. S. Ajmani, H. Huang and K. J. Schwab, Environ. Health Persp., 2013, 121, 1161.

[479] H. Ma, P. L. Williams and S. A. Diamond, Environ. Pollut., 2013, 172, 76-85.

[480] K. Van Hoecke, J. T. K. Quik, J. Mankiewicz-Boczek, K. A. C. De Schamphelaere, A. Elsaesser, P. Van Der Meeren, C. Barnes, G. Mckerr, C. V. Howard, D. Van De Meent, K. Rydzyński, K. A. Dawson, A. Salvati, A. Lesniak, I. Lynch, G. Silversmit, B. De Samber, L. Vincze and C. R. Janssen, Environ. Sci.

Technol., 2009, 43, 4537-4546.

[481] D. Lin and B. Xing, Environ. Sci. Technol., 2008, 42, 5580-5585.

[482] X. Ma, J. Geiser-Lee, Y. Deng and A. Kolmakov, Sci. Total Environ., 2010, 408, 3053-3061.

[483] D. Lin and B. Xing, Environ. Pollut., 2007, 150, 243-250.

[484] P. Miralles, T. L. Church and A. T. Harris, Environ. Sci. Technol., 2012, 46, 9224-9239.

[485] K. D. Grieger, A. Fjordbøge, N. B. Hartmann, E. Eriksson, P. L. Bjerg and A. Baun, J. Contam.

Hydrol., 2010, 118, 165-183.

[486] X. Ma, A. Gurung and Y. Deng, Sci. Total Environ., 2013, 443, 844-849.

[487] Y. S. El-Temsah and E. J. Joner, Environ. Toxicol., 2012, 27, 42-49. 
[488] T. Phenrat, T. C. Long, G. V. Lowry and B. Veronesi, Environ. Sci. Technol., 2009, 43, 195-200. [489] A. L. Dale, E. A. Casman, G. V Lowry, J. R. Lead, E. Viparelli and M. Baalousha, Environ. Sci. Technol., 2015, 49, 2587-2593.

[490] G. Lowry and E. Casman, Nanomater. risks benefits, 2009, 125-137.

[491] S. Diegoli, A. L. Manciulea, S. Begum, I. P. Jones, J. R. Lead and J. A. Preece, Sci. Total Environ., 2008, 402, 51-61.

[492] C. O. Hendren, A. R. Badireddy, E. Casman and M. R. Wiesner, Sci. Total Environ., 2013, 449, 418-425.

[493] K. Yin, I. M. C. Lo, H. Dong, P. Rao and M. S. H. Mak, J. Hazard. Mater., 2012, 227-228, 118-125.

[494] A. Praetorius, M. Scheringer and K. Hungerbühler, Environ. Sci. Technol., 2012, 46, 6705-13.

[495] S. K. Brar, M. Verma, R. D. Tyagi and R. Y. Surampalli, Waste Manage., 2010, 30, 504-520.

[496] C. Levard, E. M. Hotze, B. P. Colman, A. L. Dale, L. Truong, X. Y. Yang, A. J. Bone, G. E. Brown, R. L. Tanguay, R. T. Di Giulio, E. S. Bernhardt, J. N. Meyer, M. R. Wiesner and G. V. Lowry, Environ. Sci. Technol., 2013, 47, 13440-13448.

[497] C. Levard, E. M. Hotze, G. V. Lowry and G. E. Brown, Environ. Sci. Technol., 2012, 46, 6900-6914. [498] I. Bhatt and B. N. Tripathi, Chemosphere, 2011, 82, 308-317.

[499] S. Tresintsi, K. Simeonidis, M. Katsikini, E. C. Paloura, G. Bantsis and M. Mitrakas, J. Hazard. Mater., 2014, 265, 217-225.

[500] S.-A. Lee, K.-H. Choo, C.-H. Lee, H.-I. Lee, T. Hyeon, W. Choi and H.-H. Kwon, Ind. Eng. Chem. Res., 2001, 40, 1712.

[501] R. J. Honda, V. Keene, L. Daniels and S. L. Walker, Environ. Eng. Sci., 2014, 31, 127.

[502] Z. Xiao-hong, H. Bao-cheng, Z. Tao, L. Yan-chen and S. Han-chang, Chemosphere, 2015, 119, 568. [503] G. D. Moeser, K. A. Roach, W. H. Green, T. A. Hatton and P. E. Laibinis, AlChE J., 2004, 50, 28352848.

[504] A. Ditsch, S. Lindenmann, P. E. Laibinis, D. I. C. Wang and T. A. Hatton, Ind. Eng. Chem. Res., 2005, 44, 6824-6836.

[505] J. Sun, R. Xu, Y. Zhang, M. Ma and N. Gu, J. Magn. Magn. Mater., 2007, 312, 354-358.

[506] European Standard EN 12457-4, 2002. Characterization of waste - leaching - compliance test for leaching of granular waste materials and sludge - Part 1: One stage batch test at a liquid to solid ratio of $10 \mathrm{~L} / \mathrm{kg}$ for materials with high solid content and with particle size below $10 \mathrm{~mm}$ (without or with size reduction).

[507] U.S. EPA, Test methods for evaluating solid wastes, Toxicity Characteristic Leaching Procedure (TCLP), Method 1311 SW-846, 3rd. Ed., Washington DC, USA, 1986.

[508] S. C. Bolyard, D. R. Reinhart and S. Santra, Environ. Sci. Technol., 2013, 47, 8114-8122.

\section{TOC graphic}

This review article summarizes recent research in the field of inorganic engineered nanoparticles development with direct or potential interest for drinking water treatment.

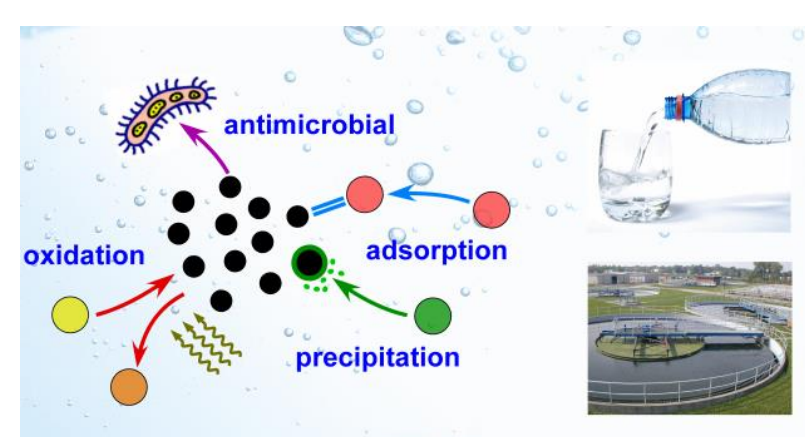

